\title{
Phylogeny of the Basal Lineages of Suborder Brachycera (Diptera) in Egypt
}

\author{
Sara A. Al-Ashaal' ${ }^{1}$ Haitham B. M. Badrawy ${ }^{2}$, Rabab F. Sawaby ${ }^{3}$ and Salwa K. \\ Mohammad \\ Department of Entomology, Faculty of Science, Ain Shams Univ., \\ Abbassia- Cairo, Egypt \\ E-mail: 1 alashalsara@gmail.com; \\ 2haithambadrawy@yahoo.com; ${ }^{3}$ rabab_sawaby@yahoo.com
}

\begin{abstract}
The phylogenetic relationships among 26 taxa of Brachycera (Diptera) beside one outgroup taxa of Nematocera were studied using cladistic analysis and one PCR-amplified DNA gene segments (28S). The cladistics analysis was applied by Mesquite program (using 216 multistate characters). The taxa were sampled from various areas of Egypt. The morphometric analysis and phenotypic features were determined for the all selected brachyceran taxa to reveal the phylogenetic relationships among them. The resulted cladogram showed high degree of variations and affinities (Similarity coeffeciant ranged from 53.8 to $97.8 \%$ ). We have sequenced $205 \mathrm{bp}$ of $28 \mathrm{~S}$ gene of all taxa and the comparison of the nucleotide compositions found allows phylogenetic analyses of the suborder. The estimated net nucleotide sequence divergence among the taxa examined was found to range from 0.00 to $0.7 \%$ as an affinity. Cluster analysis based on both morphometric and sequence data showed less variation than morphometric data only (Similarity coeffeciant ranged from 60.6 to $82.5 \%$ ) of the 27 taxa. The trees obtained from combined datasets (morphology/28S gene) using (Parsimony method) revealed the radiation of the basal lineages of the suborder.
\end{abstract}

Key words: Cladistic analysis, Morphometric measures, PCR, 28S Gene, Nematocera, Bracycera, Egypt.

\section{INTRODUCTION}

Order Diptera (true flies) is one of the most species-rich, anatomically varied and ecologically innovative groups of organisms. An estimated 150.000 species of Diptera have been described (Thompson, 2005). The Diptera were traditionally divided into three suborders Nematocera, Brachycera and Cyclorrhapha but recently, dipteran species have been classified into two suborders, Nematocera and Brachycera based on the phylogenetic estimates for the Diptera (Yeates and Wiegmann, 1999; Thompson 2005, Wiegmann et al.; 2011). A major lineage within the order, the suborder Brachycera comprises the "higher Diptera," or flies with shortened antennae. This group includes many well-known members, such as fruitflies, horse flies, flowerflies, blowflies, and houseflies, and numerous less famous relatives. The Brachycera are certainly a monophyletic group, with a large number of undisputed synapomorphies (Hennig, 1973; Sinclair, 1992; Sinclair et al., 1994 ; Griffiths, 1996).

Branching lineages of Brachycera in the supertree analysis included five infraorders; Asilomorpha, Stratiomyomorpha, Xylophagomorpha, Tabanomorpha and Muscomorpha (Yeates and Wiegmann 1999; Yeates 2002; Yeates et al., 2007). Once upon a time, order Diptera in Egypt is represented by 64 families in three suborders [Nematocera (11 


\section{Sara A. Al-Ashaal et al.}

families), Brachycera (12 families) and Cyclorrhapha (41 families)] based on a list by Steyskal and El-Bialy (1967). More recently, Brachycera is represented by 53 families (within the first four infraorders) due to the combination of two suborders (Brachycera and Cyclorrhapha).

In Egypt, no phylogenetic analysis was applied as yet to the basal lineages of brachyceran flies. The greatest advances in dipteran phylogenetics over the past decade have been made by a relatively small number of authors attempting to synthesize phylogenetic data across large components of it, using quantitative methods. Analytical trends in the use of molecular sequence data for Diptera phylogenetics include employing a wide range and variety of single copy genes (Moulton and Wiegmann, 2007), and in some cases these genes may be analyzed simultaneously with morphological data (Meier and Baker, 2002).

Relationships among infraorders of Brachycera remain largely unknown, as most studies have focused on relationships below the family level, and few studies attempted to reconstruct relationships at higher taxonomic levels. At present, the most rigorous brachyceran systematics synthesizes available data from multiple molecular and/or morphological partitions, and analyzes them quantitatively (Yeates, 2007).

Our understanding of the evolution of brachyceran flies is obscured by limited and conflicting anatomical and genetic evidence as well as by the difficulty in capturing the enormous species diversity in a single comprehensive phylogenetic analysis.

Despite the shortcomings of supertree approaches (Gatesy et. al., 2002) and a number of proposed synapomorphies of Brachycera have not received widespread support. Therefore the resulting tree will be used as a point of reference in the reviewing of the current status of dipteran higher-level phylogenetics.

The purpose of this study is to understand and document the phylogenetic relationships among the basal radiation of the suborder Brachycera in Egypt, including infraorders, super-families and some representative families based on morphological and molecular datasets using phylogeny estimation methods.

\section{MATERIALS AND METHODS}

\section{Taxon sampling}

In this study the emphasis was to sample the diversity of the Brachycera (26 taxa within 12 families) beside one taxa of family Culicidae as an outgroup (Appendix 1) for both the morphological and molecular datasets in sufficient detail to permit a thorough understanding of the evolution of brachyceran flies. The morphological and molecular datasets are built on the all selected taxa.

The materials during the study were collected from Al-Qalubiya, Qena, Sharm El-Sheikh and Abbassia by using aerial net, then by aspirator, and killed by ethyl acetate and preserved in $100 \%$ alcohol or killed by freezing and kept at $-20{ }^{\circ} \mathrm{C}$. The collected specimens were used in the morphological inspection, genitalia dissection and the elaboration of dry pinned specimens to be placed in Ain Shams University Collection.

\section{Characters selection}

The morphological dataset comprises 216 multistate morphological characters of 27 taxa. The characters which relate to external and internal features of adult are listed below (Appendix 2). Autapomorphies were left in the analyses as these character states could be more widespread and useful to support clades with undiscovered or not included species (Yeates 1992, Yeates; Irwin 1996). Measurements of the insect body parts including genital systems were calibrated by ocular lens (ocular micrometer) standardized at 100 units using 


\section{Phylogeny of the Basal Lineages of Suborder Brachycera (Diptera) in Egypt}

a stereomicroscope at magnification $100 \mathrm{x}$ to 400x. Genitalia were corroded in 5-10\% $\mathrm{KOH}$ at room temperature for one day and subsequently dissected in $70 \%$ ethanol and drops of glycerin under the stereomicroscope. The genital organs were examined and drawn. Morphological terminology follows Verrall (1909), Snodgrass (1935), Dusek and Rozkosny (1970), Nagatomi and Iwata (1978), Triplehorn and Johnson (2005), Rozkosny (1982), Efflatoun (1930), Oldroyd (1952 and 1954), Chvala et al. (1972), Axtell (1976), Stoffolano and Yin (1983), and Philip and Cascaron (1971). Palaearctic catalogue of Chvala (1988) and the Biosystematic Database of World Diptera (Evenhuis et al. 2012) to obtain the updating names of different taxa.

\section{Data analysis (Multistate)}

Cladistic analyses are elaborated by the "MESQUITE" multistate computerprogram [version, 2.73, (2010)] depending on equally-weighted maximum parsimony (MP). All characters were treated as unordered. Heuristic searches were performed using 100 random replicates. The number of maximum trees saved to memory was set to 1000 due to computational limitations.

\section{PCR technique \\ Samples preparation}

Genomic DNA was extracted from dried as well as preserved specimens in alcohol that stored in the freezing at $-20^{\circ} \mathrm{C}$ until used. The preserved samples in $100 \%$ Alcohol were washed with distilled water several times for removing the alcohol Haymer and Me Innis (1994).

\section{DNA extraction}

The genomic DNA was extracted from 27 taxa of thirteen dipterous families and the whole body tissues of insects were used for DNA extraction according to Sambrook et al. (1989), Hunt and page (1995), Arif et al. (2010). The DNA pellet was dissolved in 30-50 $\mu \mathrm{l}$ of TE buffer and storage at $-20{ }^{\circ} \mathrm{C}$ until used. The concentration of DNA was determined by spectrophotometric method using UV visible scanning spectrophotometer (UNICAM $\mathrm{UV} / \mathrm{V}$ is spectrometer).Genomic DNA was analyzed with a specific gene (28S) technique according to the method described by Hauser (2005).

\section{Amplification of DNA by PCR}

Primers $5.8 \mathrm{~S}$ and $28 \mathrm{~S}$ were used to amplify a $400 \mathrm{bp}$ fragment (5.8S (5'- TGT GAA CTG CAG GAC ACA);(28S (5'- TTG CTT AAA TTT CAG GGG GT). Amplification was carried out using standard three-step PCR with an annealing temperature of $52^{\circ} \mathrm{C}$. PCR amplifications were performed in a total volume of $25 \mu \mathrm{l}$ containing 10mM Tris-HC1 pH 8.3, $50 \mathrm{mM}$ $\mathrm{KC} 1,1,5 \mathrm{mM} \mathrm{MgC} 12,100 \mu \mathrm{M}$ dNTP, 10 pM primer, $1.5 \mathrm{U}$ Taq polymerase and $25 \mathrm{ng}$ genomic DNA. Amplifications were carried out in a thermocycler (Primus-Germany): first cycle $94^{\circ} \mathrm{C}$ for $1 \mathrm{~min}, 52^{\circ} \mathrm{C}$ for $1 \mathrm{~min}$ and $72^{\circ} \mathrm{C}$ for $1 \mathrm{~min}$; then 27 cycles at $94^{\circ} \mathrm{C}$ for $1 \mathrm{~min}, 52^{\circ} \mathrm{C}$ for $1 \mathrm{~min}$ and $72^{\circ} \mathrm{C}$ for 1 min. PCR products were separated in $1.5 \%$ TAE agarose gels. Gels were run at $5 \mathrm{~V} / \mathrm{cm}$ for one hour along with the $1 \mathrm{~kb}$ ladder DNA size marker (ABgene) [ranged from 0.1 to $4.0 \mathrm{~kb}$.], stained with ethidium bromide and photographed under UV light by using digital camera (Canon, Power Shot A460, 5.0 Mega Pixels).

\section{Sequencing}

Sequences of $28 \mathrm{~S}$ were first aligned using nucleotide blast (NCBI) and the result was edited by hand in (BioEdit) (205 bp) to access the homogeneity between our sequence and other sequences existed 
Sara A. Al-Ashaal et al.

already on the website. Several small regions of highly variable DNA were excluded from the analyses (195 bp was deleted) to achieve the homogeneity among the studied taxa. Unambiguous alignment gaps were treated as missing data. The alignments and phylogenetic dataset are available on request from the author.

\section{Data analysis}

Sequencing (including four base pairs, bp) was scored for each sample in the "PROBIOSYS" computer-program [version, 1.0, (2003)]. The similarity of samples was calculated based on bp sharing estimates.

\section{Combined data}

The two combined datasets $(28 \mathrm{~S}$, morphology) are applied on the 27 taxa of thirteen dipterous families, including (421 characters, multistate) that are analyzed using maximum parsimony to obtain the cladogram (Appendix 4).

\section{Cladistic method}

\section{RESULTS}

The resulted cladogram based on morphological dataset (Appendix 3) shows two main clusters. The first one is major and contains the bulk of species from suborder Brachycera and another cluster contains only one species (Culex pipiens) from suborder Nematocera as an out-group. Culex pipiens ruled out for these characters due to having long antennae (plumose in male and pilose in female), labium elongated and terminate with two small labella, the antepronotum well developed, the postpronotum poorly developed, wing with scales, scutellum trilobed, legs long and slender, forecoxa with some dark scales, abdomen elongate, epandrium and hypandrium fused, hypandrium and gonocoxites separated, Phallus without division and the absence of ejaculatory apodeme.
The first major cluster divided into two clades. The first one includes two species [Apoclea femoralis and Saropogon longicornis (Asilidae)] can distinguished from another group by the following characters; vertex convex, the presence of mystax, raptorial mouth part and the presence of bursa inseminalis in female genitalia. Apoclea sp. separated from Saropogon longicornis by the following characters; the body length, number of flagellomeres, the presence or absence of the bristles of hypopleuron, anepisternal \& notopleural, costa circumambient, the presence or absence of $R_{4}$ appendix and finally the position of $\mathrm{r}-\mathrm{m}$ to the middle of discal cell.

The second clade contains 24 taxa [Atylotus agrestis, Tabanus taeniola, Ruppellia semiflava, R. thoracica, Thereva sp., Nemotelus niloticus, Nemotelus albifacies, Nemotelus oasis, Stratiomyis longicornis, Stratiomyis anubis, Musca demostica, Fannia canicularis, Sarcophaga aegyptica, Wolfahrtia nuba, Dacus longistylus, Paradesis augur, Atherigona laevigata, Atherigona orientalis, Eristalinus taeniops, Bombylius numidus, Anthrax sp., Eupeodes corollae, Megaselia scalaris, Vermileo vermileo]. Vermileo vermileo (Vermileonidae) has evolved early out of the rest of the species according to the absence of lacinia, mandible, maxillary palp, maxila \& pseudotrachea, elongate stoutly abdomen with incomplete median longitudinal stripe, and retracted female abdominal segments 810.

The following two species, Atylotus agrestis \& Tabanus taeniola (Tabanidae) evolved from the rest 21 species depending on head broader than thorax, ocelli absent, frontal index in female, shape of pedicel, length of antennae, sclerotized epipharynx, forked of wing vein $\mathrm{R}_{4+5}$, number of abdominal stripes and aedeagus fused to parameres at apex forming phallus. 


\section{Phylogeny of the Basal Lineages of Suborder Brachycera (Diptera) in Egypt}

Atylotus separated from Tabanus by the head shape, presence or absence of calli in female Tabanus, and the presence or absence of $\mathrm{R}_{4}$ appendix.

The next five species, Nemotelus oasis, N. niloticus, N. albifacies, Stratiomys longicornis \& S. anubis (Stratiomyidae) evolved from the rest 16 species based on the following characters: ocelli located on ocellar tubercle, small and hexagonal discal cell.

Stratiomyis spp. (Stratiomyinae) is distinguished from Nemotelus spp. (Nemotelinae) by the following characters; wings with or without $\mathrm{m}$-cu cross vein, vein $\mathrm{Cu}_{1}$ arising from discal cell or second basal cell, type of antennae and shape of head (with or without facial projection). The differentiation among Nemotelus spp. are based on the length and color of facial projection, coloration of notopleural suture and the pattern of abdomen. While Stratiomys longicornis is differed from $S$. anubis by; number of flagellomeres, shape of patterns on terga 4, shape of median process of synsternum in male, occiptal pattern in female.

Fannia canicularis (Fanniidae) has evolved out of the rest of species according to phallus undivided.

The following three species, Musca domestica, Atherigona laevigata \& A. orientalis (Muscidae) evolved from the rest 12 species depending on width of frons in female less than half width of head. Musca domestica separated than Atherigona spp. by the following characters: head quadrangular in profile, eyes dichoptic in male, postocellar bristles parallel, width of frons in male more than 1/4 width of head, thorax with 3 stripes, presence of arolium \& spotted abdomen. While Atherigona laevigata easily distinguished than $A$. orientalis by the position of $\mathrm{r}-\mathrm{m}$ either before or after the middle of discal cell, the presence of spots on the male or female abdomen, female abdomen with horseshoe-shape mark on tergite 3 and 4 and hypopygial prominence in male.

The next two species, Sarcophaga aegyptica \& Wohlfahrtia nuba (Sarcophagidae) evolved from the rest 10 species based on the presence of hypopleuron with bristles, vertical row of setae on meron and uterus or ovisac. Sarcophaga is differed from Wohlfahrtia by; arista not plumose, abdomen spotted and not check-board abdomen.

The following two species, Paradesis augur \& Dacus longistylus (Tephritidae) evolved from the rest 8 species depending on the presence of occiput developed into two lateral swellings, anterior part of terga 2 in male with complete transverse band and segment 8 transformed into piercing stick. Paradesis separated from Dacus by the following characters; length of head at most longer than half highest of head, highest of head at most more than half width of head, convergent inner vertical bristles, absence of outer vertical bristles, presence of postpronotal (humeral) setae, acrostichal bristles, dorsocentral bristles, and lateroscutellar bristles, two or more notopleural bristles, wing without maculae, $\mathrm{A}_{2}$ present, abdomen with longitudinal stripe. In female, abdomen with median longitudinal stripe and terga 2 \& 3 with incomplete transverse band in anterior part, while terga 4 with incomplete transverse band in posterior part, and ovipositor longer than abdomen.

The next two species, Eristalinus taeniops \& Eupeodes corolla (Syrphidae) evolved from the rest 6 species according to head broader than thorax, eyes with pubescence, ocelli located on ocellar tubercle, shape of head profile, shape of scape and $\mathrm{M}_{1+2}$ jointed with $\mathrm{R}_{4+5}$. Eristalinus is differed from Eupeodes by the presence or absence of eyes' markings in 
Sara A. Al-Ashaal et al.

both sexes of dried specimens, the origin of $\mathrm{Rs}, \mathrm{M}_{1}$ fused or not with $\mathrm{CuA}$, relative lengths of basal and discal cells, spurious vein vestigial or not, r-m cross vein before or after middle of discal cell, $\mathrm{R}_{4} \& \mathrm{R}_{5}$ with or without loop, present or absent of stigmal cross vein and pterostigma, segments 6-10 retracted or not.

Megaselia scalaris (Phoridae) has evolved out of the rest of species according to length of head less than half highest of head, shape of clypeus, the status of ocellar and verticle bristles, presence of vibrissae, shape of pedicel, length of of antennae, the site of arista insertion, width and shape of thorax, looped $\mathrm{R}_{5}$, $\mathrm{T} 1-2$ fused into syntergum, design of abdominal patterns, hypopygium circumversion, rotated permanently through $360^{\circ}$, position of hypopygium asymmetrical, emarginated the posterior margin of epandrium, hypandarium fused with gonocoxite to form ventral plate, the width of hypandarium and retracted of female abdominal segments 610.

The following two species Anthrax sp. \& Bombylius sp. (Bombyllidae) evolved from the rest three species of Therevidae based on body shape bee like, head narrower than thorax, width of head, shape of head profile, status of postocellar bristles, lengths of scape, pedicel \& flagellum, setose of proepisternum (propleuron), number of scutellar bristles, setose of upper and lower calypter, Rs two-branched, $\mathrm{M}_{1}$ jointed with $\mathrm{R}_{5}$, lengths of basal and discal cells, shape of cubital cell, abdomenal patterns, and the length of spermathecal ducts. Anthrax is differed from Bombylius by; the width of head, size of eyes, shape of scape, number of flagellomeres, the type of mouth-parts, thoracic patterns, the presence or absence of anepisternal bristles, the origin of vein $R_{2+3}$, the branched or fused of vein $R_{4+5}$, the presence or absence of $R_{4}$ appendix \& vein
$\mathrm{A}_{2}$ and the position of $\mathrm{r}-\mathrm{m}$ to the middle of discal cell.

In Therevidae, According to hind femur with adpressed pile of scaly hairs, design of abdominal patterns and costa circumambient with continuous around the wing, weakened along the posterior margin, Thereva sp. evolved from both species of Ruppellia semiflava \& $R$. thoracica which were distinguished to each other depending on number of dorsocentral bristles, number of flagellar styles and shape of gonostyli.

\section{PCR technique and sequencing}

Of the $400 \mathrm{bp}$ analyzed for $28 \mathrm{~S}$ were parsimony informative. Sequences of $28 \mathrm{~S}$ were first aligned using nucleotide blast (NCBI) and the result was edited by hand in (BioEdit) (205 bp) to access the homogeneity between our sequence and other sequences existed already on the website.

Several small regions of highly variable DNA were excluded from the analyses (195 bp was deleted) to achieve the homogeneity among the studied taxa. Although the exclusion of data from the phylogenetic analyses could result in a loss of phylogenetic information, these parts were excluded because there was a potential of misaligning them and introducing an erroneous signal. Most of the conservative regions of $28 \mathrm{~S}$ could be aligned unambiguously. Unambiguous alignment gaps were treated as missing data.

It is obvious from the cladogram based on molecular dataset, the low degree of variations and affinities (similarity coefficient ranged from 99.7 to $100 \%$ ) (Appendix 4) among the 27 taxa of dipteran flies.

\section{Combined data}

The resulted cladogram based on combined dataset (Multistate) (Appendix 5) shows two main clusters. The first one 


\section{Phylogeny of the Basal Lineages of Suborder Brachycera (Diptera) in Egypt}

contains the bulk of species from suborder Brachycera and another cluster contains only one species (Culex pipiens) from suborder Nematocera as an outgroup. Culex pipiens ruled out due to having long antennae (plumose in male and pilose in female), labium elongated and terminate with two small labella, the antepronotum well developed, the postpronotum poorly developed, wing with scales, wing with vein $\mathrm{R}_{2}$ that at least as long as $\mathrm{R}_{2+3}$ wing with vein $R_{3}$, scutellum trilobed, legs long and slender, forecoxa with some dark scales usually mostly dark, abdomen elongate, epandrium and hypandrium fused, hypandrium and gonocoxites separated, phallus without division, the absence of ejaculatory apodeme.

The first major cluster was divided into two clades, the first one has genus Vermileo according to the abdominal stripes with incomplete median longitudinal stripe, the absence of alula or axillary lobe, abdomen stoutly elongate and apical female abdominal segments 8-10 retracted.

The second clade contains 25 species that divided into two monophyletic groups according to the shape of pedicel, proportion between lengths of style to length of flagellum, fork of wing vein $\mathrm{R}_{4+5}$, number of abdominal stripes, shape of aedeagus. The first monophyletic group contains only two species [Tabanus taeniola and Atylotus agrestis (Tabanidae). Tabanus separated from Atylotus based on the head shape, presence or absence of calli in female, and the presence or absence of $\mathrm{R}_{4}$ appendix.

The second monophyletic group has two groups. The first group includes three species (Nemotelus spp.) can distinguished from another group due to head triangular in profile (with facial projection), veins $\mathrm{R}_{1}+\mathrm{R}_{2}+\mathrm{R}_{3}$ united. Nemotelus albiefacies differs from other Nemotelus spp. in the design of the abdominal patterns, antennal index and the color of subnotopleural suture and facial projection. Nemotelus oasis differs from Nemotelus niloticus by having flagellum with 6th flagellomere longer than 5 th flagellomere, postalar calli pale whitish colored, the abdominal patterns of both sexes, facial projection less than $2 / 3$ of eyelength in male and frontal spots present in female.

The second group has two subgroups. The first subgroup has two branches, the first one has two clusters, the first cluster include Apoclea, Ruppellia thoracica and Saropogon longicornis together due to the status of wing vein $\mathrm{R}_{4+5}$ (fused or branched). Apoclea differs from Ruppelia and Saropogon due to the body length in both sexes, length of style, number of flagellum segments, hypopleuron with or without bristles, costa circumambient, continuous around the wing, weakened along the posterior margin or abbreviated, ending at or before $\mathrm{M}_{2}$ and $\mathrm{R}_{4}$ vein with or without recurrent appendix.

Saropogon longicornis differs from Ruppellia thoracica in width of head, head in profile, shape of vertex, size of eyes, the presence of ocelli, ocellar bristles \& mystax, shape of pedicel, length of antennae, type of mouth parts, the presence of postpronotal (humeral) setae, the presence of proepisternum (propleuron) \& acrostichal bristles, the origin of Rs, lengths of basal and discal cells, length of abdomen, epandrium shallowly notched or posterior margin straight or posterior margin deeply emarginate, forming U-shape with basal connection and shape of gonostyli \& phallus.

The second cluster includes Ruppellia semiflava, Thereva sp. and Bombylius numidus. Ruppellia semiflava differs from both Thereva and Bombylius in costa circumambient, continuous around the wing, weakened along the posterior margin or abbreviated, ending at or before $\mathrm{M}_{2}$ and the shape of gonostyli. Thereva differs from 
Sara A. Al-Ashaal et al.

Bombylius in the body shape, width of head, head in profile, shape and length of scape, proportion between lengths of antennae to length of flagellum, width of basal flagellomere, annulations of flagellum, number of flagellum segments, type of mouth parts, number of thoracic stripes, presence of supra-alar \& dorsocentral bristles, presence of upper \& lower calypter, presence of arolium, design of abdominal pattern and shape of gonostyli.

The second branch has two clusters, the first one has Anthrax sp., Megaselia scalaris and Eupeodes corollae, Anthrax differ than the other two taxa by the shape of clypeus (appear as a small sclerite Ushaped), width of frons in female, type of antennae, shape of scape, shape of pedicel, annulations of flagellum, number of flagellum segments, thorax with transverse suture, presence of precoxal bridge, presence of supra-alar, post-alar \& posterior anepisternal bristles, presence of small triangular sclerite found behind midcoxa, costa circumambient, continuous around the wing, size of cubital cell, presence of arolium, design of abdominal pattern, number of observed abdominal segment, syntergosternite comprised of at least fusion of sternite and tergite of segment 8, shape of hypopygium \& hypandarium, and shape of spermathecae, Megaselia scalaris can distinguished from Eupeodes corollae in the following characters; body shape, length of head, size of eyes, shape of face, presence of ocellar bristles, presence of vibrissae, shape of scape, length of arista, site of arista insertion, thoracic shape, presence of upper $\&$ lower calyptera, origin of Rs, presence of vein $\mathrm{R}_{2+3}$, size of discal, medial \& basal cells, presence of spurious vein, and presence of pterostigma.

The second cluster includes two subclusters; the first one contains Eristalinus and Dacus, while the second sub-cluster contains Paradesis and wohlfahrtia.
Eristalinus differs from Dacus in body shape, head in profile, eyes' markings in dried specimens in both sexes, presence of ocelli, frontal suture \& vibrissae, shape of face, occiput developed into two lateral swelling, shape of scape \& pedicel, width of thorax, presence of postpronotal (humeral) setae, presence of acrostichal, supra-alar, notopleural \& scutellar bristles, presence of upper \& lower calypter, presence of dark spots at the tip of the wing, $M_{1}$ fused with $\mathrm{CuA}$, size of medial \& cubital cells, presence of spurious vein, mid tibial spurs, arolium \& empodium, number of abdominal stripes, terga 1 with dark maculae, length of female ovipositor, shape of syntergosternite, and shape of spermathecae.

Paradesis and wohlfahrtia differs from each other in width, length and highest of head, pedicel with or without seam, number of thoracic stripes, thorax with transverse suture, presence of postpronotal (humeral) setae, hypopleuron with or without bristles, presence of acrostichal, post-alar bristles \& dorsocentral bristles, presence of upper \& lower calypter, wing with or without maculae, design of abdominal pattern, length of female ovipositor, and shape of spermathecae.

The second subgroup includes seven species can distinguished from the second subgroup by the outer vertical bristles are parallel.

The first subgroup contains two branches; the first branch has three taxa within two genera Sarcophaga and Atherigona spp. this differs in width, length and highest of head, head in profile, direction of ocellar and inner vertical bristles, width of frons in female, the site of arista, number of stripes on thorax, presence of hypopleuron, anepisternal \& katepisternal bristles on thorax, and the presence or absence of arolium and empodium.

The second branch has two clusters, the first one includes Musca and Fannia that 


\section{Phylogeny of the Basal Lineages of Suborder Brachycera (Diptera) in Egypt}

differs from the second cluster including Stratiomys spp. in width, length and highest of head, the presence of ocelli \& frontal suture, the shape of clypeus, the presence of ocellar, postocellar, inner \& outer verticle, and postverticle bristles, the presence of vibrissae, type of antennae, shape of scape \& pedicel, length of antennal flagellum, width of basal flagellomere, annulations of flagellum, the presence of postpronotal (humeral) setae, the presence of acrostichal, supra-alar, post-alar, dorsocentral, posterior anepisternal, katepisternal, anepimeral \& notopleural bristles, the presence of upper $\&$ lower calypter, $\mathrm{M}_{1}$ fused with $\mathrm{CuA}$, size of discal \& cubital cells, abdominal pattern, syntergosternite comprised of at least fusion of sternite and tergite of segment 8, hypopygium circumversion, rotated permanently through $360^{\circ}$, position of hypopygium, number of observed abdominal segment, shape of epandrium \& hypandarium.

Musca can separate from Fannia by thorax with four stripes, proepisternum (propleuron) dorsally setose and terga 1 with dark maculae. Also, Stratiomys anubis is distinguished from S. longicornis by having: six flagellomeres, large and distinct abdominal side-markings and fused sidemarkings on tergum 4 in both sexes; but in male, broadened synsternum and median process with small incision posteriorly, while in female, occiput with one yellow spot, vertex with two yellow spots, yellow postocular band and genital furca longer than wide.

\section{DISCUSSION}

This work intends to combine the morphological interpretations (216 characters in "multistate") with the nucleotide sequence data (28S ribosomal DNA gene) for 27 taxa to improve estimates of the brachyceran evolutionary relationships.
The topology of all trees from different analyses shows the major dipteran higher categories such as Muscomorpha including Schizophora, Acalyptrata and Calyptrata are monophyletic, and Nematocera (as outgroup), Orthorrhapha (including Asilomorpha, Stratiomyorpha, Tabanomorpha) and Aschiza are paraphyletic. This result is congruent with the studies of 1989, McAlpine 1989, Sinclair et al. 1994; Cumming et al. 1995; Oosterbroek and Courtney 1995, Yeates and Wiegmann, 1999; Yeates, 2002; Weigmann et al. 2011 that showed their supertree analysis except some unexpected results referring it in their specific section.

Also, the relationships inferred from the result are consistent with those from recent morphological of (Yeates, 2002) and molecular of (Wiegmann et al., 2000) analyses and agreed in large part with expected relationships from conventional classifications of (Griffiths, 1994; Sinclair et al., 1994; Yeates and Wiegmann, 1999).

The present study provides increased resolution of brachyceran phylogeny. Ongoing phylogenetic analyses that span the diversity of the suborder shall establish a robust phylogeny of the group with increased quantitative rigor. This will enable a more precise understanding of the evolution of the morphology of flies.

The present results agree with Wiegmann et al.(2011) that the phylogenetic relationship and molecular studies within suborder Brachycera is not easy due to the complicated structural characters, the number of families, genera and species within suborder is large and the using of number of genes.

\section{Basal Relationships of the Brachycera}

The Parsimony method (Multistate) of the combined morphological and molecular data support for the monophyly of the Brachycera and Muscomorpa, and for 
Sara A. Al-Ashaal et al.

the paraphyly of the three brachyceran infraorders: Asilomorpha, Stratiomyomorpha and Tabanomorpha. That is agreeing with the following studies (1989; Yeates and Wiegmann, 1999; Yeates, 2002).

\section{Outgroup of Brachycera Lower Diptera (Nematocera)}

We are used the Culex, Culicidae, Culicimorpha (Nematocera) as an outgroup to suborder Brachycera.The paraphyly of this assemblage (=Nematocera) was demonstrated in recent cladistic analyses (Sinclair 1992, Oosterbroek and Courtney 1995, Blagoderov et al., 2007). The present study strongly supported Culicomorpha as a separated clade of lower dipteran flies.

\section{Brachycera \\ (Monophyly)}

The Brachycera is certainly a monophyletic group; with a large number of undisputed synapomorphies (yeates and Wiegmann, 1999). Their adults are more stout-bodied and compact than those of the lower Diptera (Hennig 1973, 1989, Sinclair 1992, Sinclair et al., 1994; Griffiths, 1996).

A number of proposed synapomorphies of Brachycera have support it as a monophyletic group such as some specific characters of male genital system like lateral ejaculatory processes and ejaculatory apodeme represent only in brachyceran flies.

The earliest branching lineage of Brachycera contains two Infraorders, Stratiomyomorpha and Tabanopmorpha as decision of Yeates (2002).

\section{Relationships of Infraorders}

The results agree with Yeates and Wiegmann (1999) that the relationships among the four infraorders of Brachycera (Asilomorpha, Stratiomyomorpha,
Tabanomorpha, and Muscomorpha) remain unresolved.

Certain adult features such as Radial vein distribution crowded towards costal margin, discal cell small and hexagonal in shape, $\mathrm{R}_{5}$ ending before wing apex support a basal clade of Brachycera that excludes Stratiomyomorpha alone. Also the two subfamilies (Nemotelinae and Stratiomyinae) of Stratiomyidae are far away and not linked to each other.

The remaining groups of Brachycera may be united by the presence of lateral ejaculatory sclerites in the male genitalia which are used as evidence of synapomorphy among the infraorders Tabanomorpha and Asilomorpha. The complex organ that called phallus (male genital system) was proposed as a synapomorphy of Stratiomyomorpha and Muscomorpha. Also, still the interpretation of this structure in Brachycera was disputed.

\section{Lower Brachycera (Asilomorpha, Tabanomorpha) \\ Stratiomyomorpha,}

Lower brachycera is differentiated from the higher by the possession of antenna that evolved through progressive fusion of segments and specialized sensory functions and divided into a postpedicel and stylus as mentioned by Stuckenberg (1999).

The present study revealed weak evidence for the monophyly of a clade containing Asilomorpha, Stratiomyomorpha and Tabanomorpha as shown in our trees.

The families Asilidae, Therevidae and Bombyliidae have been united in Asilomorpha on the basis of the apomorphic position of the shape and length of style, the position of hypopogium and aedeagus as mentioned by Yeates (1994). A number of asiloid families have received critical phylogenetic scrutiny in recent years. The affinities of this group remain obscure, with some authors placing them inside or near 


\section{Phylogeny of the Basal Lineages of Suborder Brachycera (Diptera) in Egypt}

Therevidae such as Yeates 1994 and Sinclair et al. (1994).

Vermileonidae is related as a sister group to Tabanidae within Tabanomorpha due to the affinities among them in the following characters: shape of head and aedeagus, shapes of upper and lower calypter, frontal index in female, type of mouth-parts, presence or absence of mid tibial spur and abdomenal patterns as reported by Nagatomi et. al. (1999).

In the present study, trees within Stratiomyomorpha, the two subfamilies (Stratiomyinae and Nemtelinae) are separated to each other by the shape of head profile as Badrawy (2006) mentioned.

\section{Tabanomorpha}

Vermileonidae is ruled out of the Tabanidae based on abdomen is elongate and without complete median longitudinal stripe. In addition, shape of head and aedeagus, the absence of alula (axillary lobe) and presence or absence of mid tibial spur.

Our trees confirmed the separation of the two genera Tabanus and Atylotus (Tabaninae, Tabanidae) as Abu El-Hassan $e t$ al. (2011) mentioned. Their adults feed on nectar and pollen, except for most female Tabanidae that feed on vertebrate blood.

Synapomorphies for Tabanomorpha need reevaluation with the inclusion of this distinctive family (Tabanidae) as separated in our trees.

Tabanomorpha relationships revealed by $28 \mathrm{~S}$ ribosomal DNA sequence data (Wiegmann et al., 2000) were similar to those generated using morphological data (Yeates, 2002), including paraphyly of the infraorder and its families including the Vermileonidae. In our tree, we agree with these results.

\section{Stratiomyomorpha}

Synapomorphies for Stratiomyidae include loss of tibial spurs on adult prothoracic legs, costal vein terminating at $\mathrm{M}_{2}$, and male genitalia. A pioneering morphological and molecular phylogenetic study in the Stratiomyidae showed Stratiomyinae was not monophyletic, but Nemotelinae was monophyletic. (Badrawy, 2006; Brammer and von Dohlen, 2007).

The subfamily Nemotelinae (genus Nemotelus) completely separated from the subfamily Stratiomyinae (genus Stratiomys) based on the presence of facial projection of Nemotelus.

All trees confirmed the distinctively between the three species of genus Nemotelus ( $N$. albifacies, $N$. niloticus, $N$. oasis). Where, our results support Mohammad et al. (2009) decisions for removing albifacies and oasis from synonymy with niloticus.

Also, Stratiomys anubis is not linked to $S$. longicornis as shown in our trees. This result supports Badrawy (2006 \& 2014 in press) decision in elevating the $S$. anubis to a distinct species and not placed as a synonym of S. longicornis as suggested by Rozkosny (1982 \& 2001).

Analysis of the combined morphological and molecular data strongly favors a monophyletic basal lineage of (Stratiomyomorpha (except subfamily Nemotelinae) and Tabanomorpha).

\section{Asilomorpha}

The Asilomorpha (Bombyliidae, Asilidae and Therevidae) is not monophyletic, and support for relationships among these families is high against the suggestion of Yeates (2002).

Therevidae is related as a sister group to Asilidae within Asilomorpha due to the affinities among them in the following characters: shape of vertex, the presence or absence of mystax, the type mouth parts and the shape of genitalia. The therevid subfamilies Phycinae and Therevinae are monophyletic and we agree with Yang et al. 
Sara A. Al-Ashaal et al.

(2000) tree. Also, all trees support Badrawy and Mohammad (2011) decisions, that they recognized two distinct species of Ruppellia semiflava and Ruppellia thoracica of family Therevidae.

The present trees support to differentiate among the two subfamilies (Apoclinae and Saropoginae) of family Asilidae as Geller-Grimm and Artiga (2004) support the classification of the family.

Also, our trees support to distinguish among the two subfamilies (Bombyliinae and Anthracinae) of family Bombyliidae in two different clades depending on shape of scape, number of flagellomeres, the type of mouth-parts, thoracic patterns and the position of $r-m$ to the middle of discal cell.

\section{Muscomorpha}

The infraorder Muscomorpha contains all brachyceran families except those belonging to Stratiomyomorpha, Tabanomorpha and Asilomorpha Synapomorphies include loss of tibial spurs, antennal flagellum with 1-4 flagellomeres, and a single plate in the female cercus, the base of epandrium articulated on gonocoxites, and gonostyli moving obliquely or dorsoventrally.

\section{Cyclorrhapha}

In the present study, cyclorrhaphan monophyly is well supported as suggested by Griffiths (1972), Stoffolano et al. (1988), McAlpine (1989), Cumming et al. (1995) and Melzer et al. (1995) based on the following synapomorphies: absence of adult abdominal design, absence of gonocoxal apodemes, presence of surstyli, shapes of head, scape \& pedicel and the presence or absence of mid tibial spurs.

Cyclorrhapha have traditionally been divided into two groups, Aschiza and Schizophora, based on the absence or presence, respectively, of a ptilinal fissure (frontal suture) (McAlpine, 1989).

\section{Ashiza}

\section{(Lower Cyclorrhapha)}

The ashizan families, in this study, include Phoridae and Syrphidae. Most recent studies instead have concluded that "Aschiza" are probably paraphyletic with respect to Schizophora (Griffiths, 1972, 1990; Wada, 1991; Cumming et al., 1995; Zatwarnicki, 1996) and we agrees with these studies and refers to them as lower Cyclorrhapha.

The tree analysis divides the Ashiza into two separate lineages the Phoroidea (Phoridae) and the Syrphoidea (Syrphidae). The latter clade is usually considered the sister clade of the Schizophora (inception with Tephritoidea, Tephritidae).

Also, cyclorrhapha has received increased phylogenetic scrutiny in recent molecular systematic studies based on nuclear 28S rDNA (Collins and Wiegmann, $2002 \mathrm{~b}$ ), this result agree with our result in multistate.

\section{Schizophora \\ (Higher Cyclorrhapha)}

Schizophoran flies emerge from the puparium by inflation of a membranous head sac (ptilinum). The major autapomorphies for Schizophora are features associated with this method of emergence (McAlpine, 1989). Additional schizophoran synapomorphies include the following: shortened of anal cell, presence of two pairs of vertical bristles, and presence of adventitious suture on the first abdominal segment.

Traditional views of schizophoran subdivision depend on the size of the lower calypter, hence the names for the two divisions of the group (Acalyptratae and Calyptratae). 


\section{Phylogeny of the Basal Lineages of Suborder Brachycera (Diptera) in Egypt}

It has long been recognized that this character is too variable in both groups to be a reliable synapomorphic or diagnostic feature. Several workers have reviewed the evidence and classificatory history of Schizophora.

\section{Acalyptratae}

The major synapomorphies of this group are: males' dichoptic, reduced lower calypter, loss of the postclypeus, two of three spermathecae with a common duct, pre- and postsutural inter-alars, presutural dorsocentrals, pre- and postsutural acrostichals, ventral scutellar bristles, katepimeral bristles, meral brisles, and laterotergal bristles.

Griffiths (1972) argued against acalyptrate monophyly and listed synapomorphies for the five basal schizophoran superfamilies in his system but did not resolve relationships among them. He inserted the rank prefamily between superfamily and family in his system; while McAlpine inserted the rank of suprafamily at the same location in his system, considerably increasing their complexity.

The family concept in Acalyptratae is narrower than the family concept used elsewhere in Diptera. In one sense this is unimportant because the levels of taxonomic rank are arbitrary. However, if dipteran families are used as measures of biodiversity, then the disparity in family rank across the order is important.

The tree analysis supports acalyptrate group, including TephritoideaTephritidae, as a monophyletic on the branching lineage as mentioned by Wada (1991), Skevington and Yeates (2000), Collins and Wiegmann (2002a). Also the tree placed Tephritidae (Acalyptratae) as a sister clade along with Sarcophagidae (Calyptratae) in the superfamily Oestroidea.

There are still no comprehensive quantitative phylogenetic analyses of
Schizophora. McAlpine (1989) and, less strongly, Hennig (1973) favored a monophyletic Acalyptratae as sister-group to Calyptratae and we agree with this decision.

\section{Calyptratae}

Calyptratae have long been recognized a major lineage of higher Diptera, and the morphological support for this clade is stronger than for any other schizophoran group. Synapomorphies include the following: with such convincing autapomorphies as a pedicellar cleft, prestomal suture, complete transverse line on scutum, lower calypter, and alternating strong and slender costal setae as mentioned by Griffiths (1972), Hennig (1973), Hackman and Vaisanen (1985), McAlpine (1989), Michelsen (1991).

A number of proposed calyptrate synapomorphies are either reversed in some calyptrate subgroups or also found in some acalyptrate subgroups. Calyptratae is comprised of some of the more diverse and successful fly families, including Calliphoridae, Sarcophagidae, Tachinidae, Anthomyiidae, and Muscidae.

Muscoidea and Oestroidea were united as sister-groups by the apomorphic reduction of male sternite 6 , female abdominal segments 6 and 7 modified for oviposition, strongly developed vibrissae, a close connection between surstyli and cerci, and a female hypoproct with lingulae.

Early molecular studies were hampered by excessively sparse taxon sampling and few genes, and results are strongly conflicting (Nirmala et al., 2001). Until now, no comprehensive morphologial or molecular analysis has been conducted for the Calyptrata except Kutty et. al. (2010) proposed a higher-level phylogenetic hypothesis for the Calyptratae (Diptera) based on an extensive DNA sequence dataset. Their analyses as well as our study supported the monophyly of the Calyptratae 
Sara A. Al-Ashaal et al.

\section{Oestroidea}

Sarcophagidae, placed within Oestroidae, contains two far away sister clades of the two genera Sarcophaga and Wahlfahrtia based on the following characters: the type of arista and the abdominal patterns as mentioned by Shaumer and Kamal (1983).

\section{Muscoidea}

McAlpine (1989) and Hennig (1973) united Muscidae, Fanniidae and other families in the superfamily Muscoidea. Synapomorphies include the anus of the male situated above the cerci, male sternite 10 forming bacilliform sclerites. Griffiths (1972) did not regard this grouping of families as monophyletic, and Michelsen (1991) explicitly stated that the Muscoidea are the Calyptrata less Hippoboscoidea and Oestroidea.

Two families studied, within Muscoidea, the Muscidae and Fanniidae. Muscidae contains two sister groups including the two genera Atherigona and Musca based on shape of head profile, the size of eyes in male, the width of frons to width of head, the number of thoracic stripes, presence or absence of arolium and abdominal design.

While Fanniidae (represented by Fannia), in this study, is more related to Musca than Atherigona depending on the number of thoracic stripes, the setose of proepisternum and the maculated terga 1. The phylogeny of Fanniidae has been little studied. Relationships within Muscidae are increasingly scrutinized by morphological (Couri and Carvalho, 2003; Nihei and Carvalho, 2007) and molecular (Nihei et al., 2007) data.

\section{General Comments:}

The results of the current cladistic analysis increased our understanding of the phylogenetic relationships among the basal lineages of brachyceran flies in Egypt.

In this study the morphological and the molecular datasets were analyzed both in combination and separately to compare resulting trees, following proponents of both approaches (Kluge 1989, Lanyon 1993, Miyamoto \& Fitch 1995). Due to the larger amount of data, combining datasets may result in more robust and resolved trees. On the other hand, when combining datasets a weak but correct signal of one dataset could be overpowered by a random or incorrect signal of another dataset therefore, it is potentially useful to analyze the datasets separately.

In general, the cladistic analysis based on morphological dataset only is most consistent with the conventional classification of the suborder Brachycera.

The cladistic taxonomy allowed giving efficient summarization of phenetic similarities and affinities; it is difficult for the human mind to manipulate efficiently a large volume of multivariate data for any sizable taxonomic method and testing the numerical methods to provide the opportunity to re-examine existing or proposed variations using different methodologies.

Although, these results (which produced from combined morphological/molecular datasets) provide some good information on phylogeny of suborder Brachycera, as well as it supports for aspects of the existing classification, we found that unexpected results which reflected the conflicting hypothesis of relationships arising from classical taxonomy as follows:

- Subfamily Stratiomyinae came far from subfamily Nemotelinae in family Stratiomyidae, Sarcophaga aegyptica closer to family Muscidae than to Wohlfhartia nuba. 


\section{Phylogeny of the Basal Lineages of Suborder Brachycera (Diptera) in Egypt}

\section{Conclusion:}

Our phylogenetic estimate of suborder Brachycera relationships provides an evolutionary framework for future comparative work on species that are critically important to both society and science. Our phylogeny of flies reveals Brachycera experienced three episodes of rapid radiation lower Diptera lower Brachycera and Schizophora.

We will look to increased sampling of both taxa and sequence data, along with the development of additional genomic character systems, such as miRNAs. We challenge future workers to increase the taxonomic scope of higher-level analyses and connect these traditional boundaries of phylogenetic investigation.

\section{Acknowledgements}

Our thanks are offered to the curators of the Cairo University Collection (CUC), Entomology Department, Faculty of Science, Cairo University for their kind help. We also thank Dr. Adrian Pont, (Honorary associate curator), Natural History Museum, Oxford University, UK, who kindly provided some valuable advice. In the end, a very special thanks to Dr. Markus Friedrich Associate Professor Department of Biological Sciences Department of Biological Sciences, Wayne State University, for providing me the software programs that I used for this research. This publication comprises part of the author's M.Sc. thesis.

\section{REFERENCES}

Abu El-Hassan, G.M. (2011). Taxonomic and phylogenetic studies on family Tabanidae (Diptera: Brachycera) in Egypt, thesis submitted in particular Fulfillment of the requirements for the degree of M.Sc. in (Entomology), Entomology Department, Faculty of Science, Ain Shams Univ., 215 pp.
Arif, M.; Bakir, A.; Khan, H.A.; Al Farhan, A.H. and $\mathrm{Al}$ Homaidan, A.A. (2019). Application of RAPD for molecular characterization of plant species of medicinal value from an arid environment, A.H. Bahkali, M. Al Sadoon and M. Shobrak. Genetics and Molecular Research 9 (4): 2191 9198.

Axtell, R. C. (1976). Horse flies and deer flies (Diptera: Tabanidae). In: L. Cheng (Ed.), Marine insects, pp. 415-445.

Badrawy, H.B.M (2006). Taxonomic studies including numerical taxonomy of family Stratiomyidae (Diptera: Brachycera) from Egypt, Thesis submitted in particular Fulfillment of the requirements for the degree of M.Sc. in (Entomology), Entomology Department, Faculty of Science, Ain Shams University, $270 \mathrm{pp}$.

Badrawy, H.B.M. (2014). A Review of the subfamily Stratiomyinae Latreille (Diptera: Stratiomyidae) from Egypt (in press, submitted in the $8^{\text {th }}$ International Congress of Dipterology - 10-15 August, 2014, Potsdam, Germany).

Badrawy, H.B. and Mohammad, S.K. (2011). Review of Ruppellia Wiedemann, $1830 \quad$ (Diptera: Therevidae) in the Middle East, Zootaxa, 3097: 35-44.

Becker, T. (1905). Katal. Palaark. Diptera, 4: 108-145.

Chvala, M. (1988). Tabanidae. In: A. Soos, and L. Papp (eds.) Catalogue of Palaearctic Diptera,. Vol. 5: Athericidae-Asilidae. Akademiai Kiado. Budapest. pp. 87-171.

Chvala, M.; Lyneborg, L. and Moucha, J. (1972). The Horse Flies of Europe. Entomological Society of Copenhagen, Copenhagen , Denmark .498 pp. 
Sara A. Al-Ashaal et al.

Collin, J.E. (1947). Keys to British trypetid tribes, genn., synonymical notes and corrections. Ent. Rec., 59: 1-36.

Collins, K.P. and Wiegmann, B.M. (2002a). Phylogenetic relationships and placement of the Empidoidea (Diptera: Brachycera) based on 28s rDNA and EF-1 $\alpha$ sequences. Insect Systematics and Evolution, 33, 421444.

Collins, K.P. and Wiegmann, B.M. (2002b). Phylogenetic relationships of the lower Cyclorrhapha (Diptera: Brachycera) based on 28S rDNA sequences. Insect Systematics and Evolution: 33:445-456.

Cumming, J.M.. (1989). Book review of The Empidoidea (Diptera) of Fennoscandia and Denmark. II. The Families Hybotidae, Atelestidae and Microphoridae, Fauna Entomologica Scandinavica, Vol.12, by M. Chv'ala, 1983. Can. Field Nat., 103:620.

Cumming, J.M.; Sinclair, B.J. and D.M. Wood. (1995). Homology and phylogenetic implications of male genitalia in Diptera-Eremoneura. Entomol. Scand., 26:120-151.

Dusek, J. and Rozkosny, R. (1970). Revision der Palaearktischen Arten der Gattung Lasiopa Brulle, 1832, Beitr. Ent. 0Bd. 200H. 1L2 0S. 1941. Berlin.

Efflatoun, H.C. (1929). New species of Pro machus from Egypt (Diptera: Asilidae). Bull. Soc. R. Entomol. Égypte, 13: 65-74.

Evenhuis, N.L.; Pape, T.; Pont, A.C. and Thompson, F.C. (2010). Biosystematic Database of World Diptera. Available at: http://www.diptera.org/biosys.htm.

Evenhuis, H.M.; Hermans, H.; Hilgenkamp, T.I.; Bastiaanse, L.P., et al. (2012). Frailty and disability in older adults with intellectual disabilities: results from the healthy ageing and intellectual disability study. J. Am. Geriatrics Soc., 60(5):934-8.

Hackman, W. and Vaisanen, R. (1982). Different classification systems in Diptera, Ann. Zool. Fenneci, 19: 209-219, 1982.

Hackman, W.; V“ais“anen, R. (1985). The evolution and phylogenetic significance of the coastal chaetotaxy in the Diptera. Ann. Zool. Fenn., 22:169-203.

Haymer, D.S. and Me Innis, D.O. (1994). Resolution of populations of the Mediterranean fruit fly at the DNA level using random primers for the polymerase chain reaction. Genome. 37: 244-248.

Hunt, G. J., and Page, R. E. (1995). Linkage map of the honey bee, Apis mellifera, based on RAPD markers. Genetics 139: 1371-1382.

Geller-Grimm, F. and Artigas, J.N. (2004). Key to the genera of the Nearctic subfamilies of family Asilidae. Available at http://www.gellergrimm.de/genera/nearctic/keysubfam. html.

Griffiths GCD. (1972). The Phylogenetic Classification of Diptera Cyclorrhapha, with Special Reference to the Structure of the Male Postabdomen. The Hague: Junk 56. Griffiths GCD. 1981. Book review of the Manual of Nearctic Diptera,Vol. 1. Bull. Entomol. Soc. Can., 13:49-55.

Griffiths, G.C.D. (1982). On the systematic position of Mystacinobia (Diptera: Calliphoridae). Mem. Entomol. Soc. Wash., 10:70-77.

Griffiths GCD. (1983). Book review of The Empidoidea (Diptera) of Fennoscandia and Denmark. II. General Part. Quaest. Entomol., 19:483-85. 


\section{Phylogeny of the Basal Lineages of Suborder Brachycera (Diptera) in Egypt}

Griffiths, G.C.D. (1990). Book review of the Manual of Nearctic Diptera, Vol. 3. Quaest. Entomol., 26:117-30.

Griffiths, G.C.D. (1994). Relationships among the major subgroups of Brachycera (Diptera): a critical review. Can. Entomol.126:861-80.

Griffiths, G.C.D. (1996). Review of papers on the male genitalia of Diptera by D.M.Wood and associates. Stud. Dipterol., 3:107-23

Hennig W. (1973). Diptera (Zweifl"ugler). Handb. Zool. Berlin, 4:1-200

Hering, E.M. (1941). Key to genera of Dacinae of the world B1, frucht fliegen kunde, 3: 1-25.

Kluge, A. G. (1989). A concern for evidence and a phylogenetic hypothesis of relationships among Epicrates (Boidae, Serpentes). Syst. Zool. 38. 25-7.

Kutty, S.N.; Pape, T.; Wiegmann, B. M. and Meier, R. (2010). Molecular phylogeny of the Calyptratae (Diptera: Cyclorrhapha) with an emphasis on the superfamily Oestroidea and the position of Mystacinobiidae and McAlpine's fly. The Royal Entomological Society DOI: 10.1111/j.1365-3113.00536.x.

Lanyon S. (1993). Phylogenetic framework: towards a firmer foundation for the comparative approach. Biolog. J. Linn. Soc., 49: 45-61.

McAlpine, J.F. and Wood, D.V. (1989). Manual of Nearctic Diptera, Vol. 3. Ottawa, Can: Res. Branch Agric. Can.

Meier, R. and Backer, R. (2002). A cladistic analysis of Diopsidae (Diptera) based on DNA sequence data. Insect Systematics and Evolution, 33: 325336.

Meier, R. and Backer, R. (2002). A cladistic analysis of Diopsidae (Diptera) based on DNA sequence data. Insect
Systematics and Evolution, 33: 325336.

Meier, R. (2005). Role of Dipterology in Phylogenetic Systematics: The insight of Willi Hennig. In: D.K. Yeates and B.M. Wiegmann, eds, The Evolutionary Biology of Flies. New York: Columbia University Press, pp. 45-62.

Melzer, R.R.; Panzinger, A.; Reckel, F. and Smola, U. (1995). Central nervous system of brachyceran larvae (Insecta, Diptera). Zool. Anz. 234:113-23.

Michelsen V. (1996). Neodiptera-new insights into the adult morphology and higher level phylogeny of Diptera (Insecta). Zool. J. Linn. Soc. 117:71-102.

Miyamoto, M.M. and Fitch, W.M. (1995). Testing the covarion hypothesis of molecular evolution. Mol. Biol. Evol., 12 (3): 503-513.

Mohammad, S. (1975). Ecological and taxonomic studies on the family Syrphidae in Egypt, Thesis submitted in particular Fulfillment of the requirements for the degree of M.Sc. in (Entomology), Entomology Department, Faculty of Science, Ain Shams Univ., 246 pp.

Mohammad, S. (1979). Ecological and taxonomic studies on the family Syrphidae in Egypt, thesis submitted in particular Fulfillment of the requirements for the degree of M.Sc. in (Entomology), Entomology Department, Faculty of Science, Ain Shams Univ., 246 pp.

Mohammad, S.K.; Gadalla, S. H. and Badrawy H.B.M. (2009). A revision of the genus Nemotelus Geoffroy (Diptera: Stratiomyidae) from Egypt, with one new species and three new records, Egypt. Acad. J. Biolog. Sci., 2 (2): 95-110. 
Sara A. Al-Ashaal et al.

Moulton, J. (2000). Molecular Sequence Data Resolves Basal Divergences within Simuliidae (Diptera). Systematic Entomology, 25: 95-113.

Moulton, J.K. and Wiegmann, B.M. (2004). Evolution and phylogenetic utility of CAD (rudimentary) among Mesozoicaged Eremoneuran Diptera (Insecta), Molecular Phylogenetics and Evolution, 31: 363-378.

Nagatomi, A. and Iwata, K. (1976). Female terminalia of lower Brachycera - I (Diptera), Beitr. Ent., Berlin 26: 547.

Nagatomi, A., Yang, Ch. and Yang, D. (1999). The Chinese species and the world genera of Vermileonidae (Diptera). Japan society of tropical Ecology 1: 1-154.

Niheh, S.S. and Carvalho, C.J. (2007). Phylogeny and classification of Muscini (Diptera, Muscidae). Zoolog. J. Linn. Soc., 149(4): 493532.

Neihi, P.S.; Schuhli, G.S. and Carvalho, C.J, (2009). Fannidae and Muscidae (Diptera) from Nicaragua. Rev. Nica. Ent., 69:1-10.

Nirmala, X.; Mita, K.; Vanisree, V.; Zurovec, M. and Sehna, F. (2001). Blackwell Science, Ltd Identification of four small molecular mass proteins in the silk of Bombyx mori. Insect Mol. Biol., 10(5): 437-445.

Oldroyd, H. (1952). The horseflies of the Ethiopian region. I. Haematopota and Hippocentrum. London: British Museum (Natural History), $226 \mathrm{pp}$.

Oldroyd, H. (1954). The horseflies of the Ethiopian region. II. Tabanus and related genera. London: British Museum (Natural History), 341 pp.

Oosterbroek, P. and Courtney, G. (1995). Phylogeny of the nematocerous families of Diptera (Insecta). Zool. J. Linn. Soc. 115:267-311.

Oosterbroek, P. and Courtney, G. (2002). Phylogeny of the nematocerous families of Diptera (Insecta).

Philip, S.B. and Coscaron, S. (1971). New Newtropical Tabanidae II. Three primitive undescribed Pangoniinilike flies of unusual interest from Chile. Papeis Avulsos Zool., S. Paulo, 23 (14): 127-136.

Pont, A.C. and Deeming, B. (2001). A shoot-fly Atherigona tritici sp. n. (Diptera: Muscidae), attacking wheat Triticum aestivum in Egypt. Bull. Entomolog. Res., 91: 297-300.

Pont, A.C. and Magpayo, A (1995). Muscid shoot flies of the Philippine Islands (Diptera: Muscidae, genus Atherigona Rondani). Bull. Entomolog. Res. Supplement series 3: $123 \mathrm{pp}$.

Rozkosny, R. (1982 and 1983). A Biosystematic Study of the European Stratiomyidae (Diptera), Vol. 1 and 2, W. Junk, The Hague-BostonLondon, pp. 401+431.

Sambrook, J.; Fritsch, E.F. and Maniatis, T. (1989). Molecular cloning: a laboratory manual, vol. 3. Cold Spring Harbor Laboratory Press, Cold Spring Harbor, N.Y.

Shaumer, N. and Kamal, S. (1977). Keys for identification of species of family Syrphidae (Diptera) in Egypt. Bull. de la Societe Linneenne de Lyon, pp, 373-380.

Shaumer, N. and Kamal, S. (1978). The Syrphidae of Egypt, Extrait du bulletin mensuel de la societe Linneenne de lyon, pp. 80-84.

Sinclair, B.J. (1992). A phylogenetic interpretation of the Brachycera (Diptera) based on the larval mandible and associated mouthpart structures. Syst. Entomol.17:233-52. 


\section{Phylogeny of the Basal Lineages of Suborder Brachycera (Diptera) in Egypt}

Sinclair, B.J.; Cumming, J.M. and Wood, D.M. (1994). Homology and phylogenetic implications of male genitalia in Dipteralower Brachycera. Entomol. Scand., 24: $407-32$.

Stoffolano, J.G.; Jr, L.R.S. and Yin, L.R. S. (1983). Comparative study of the mouthparts and associated sensilla of adult male and female Tabanus nigrovittatus (Diptera: Tabanidae). J. Medical Entomol., 20, 11-32.

Stoffolano, J.G.; , N.E.; Borkent, A.; Yin, L.R.S. (1988). Ultrastructural studies of the abdominal plaques of some Diptera. Ann. Entomol. Soc. Am., 81:503-10.

Steyskal, G.C. and El-Bialy Saad (1967). A list of Egyptian Diptera with bibliography and key to families. Ministry of Agriculture Technical Bulletin 3: 1-87.

Verrall, G.H. (1909). Stratiomyidae and succeeding families of the Diptera Brachycera of Great Britain, Vol. 5, London, pp. 320-439.

Wada, S. (1991). Morphological evidence for the direct sister group relationship between the Schizophora and the Syrphoidea (Aschiza) in the phylogenetic systematics of the Cyclorrhapha (Diptera: Brachycera). J. Natural History, 25(6):1531-1570.

Wiegmann, B. M.; S.C., Tsaur, S.C.; Webb, D.W.; Yeates, D.K. and Cassel, B.K. (2000). Monophyly and relationships of the Tabanomorpha (Diptera: Brachycera) based on 28S ribosomal gene sequences. Ann. Entomol. Soc. Am., 93:1031-1038.

Wiegmann, B.M.; Yeates, D.K.; Thorne, J.L. and Kishino, H. (2003). Time flies, a new molecular time-scale for brachyceran fly evolution without a clock. Systematic Biol., 52: 745756.

Wiegmann, B.M. and Yeates D.K. On-line article. Avilable at:http://www.tolweb.org/Brachycera $/ 10500$

Wiegmanna, B.M.; Trautweina, M.D.; Winklera, I.S.; Barra, N.B.; JungWook Kima; Lambkinc, D., Bertonea, M. ; Cassela, B.K.; Baylessa, K.M. ; Heimberge A.M.; Wheelerf, B.M.; Petersone, K.J.; Pape, T., Sinclairh, B.J. Skevington J.H.; Blagoderovj, V.; Caravask V., Kuttyl, S.N.; Thompson, C., Grimaldip,D.A., Beckenbachq,A.T., Courtneyr, G.W., Friedrichk M., Meierl, S.F. and Yeates, D.K. (2011). Episodic radiations in the fly tree of life. Proceedind of the National Academy of Science, USA. 108(14): 5690-5695.

Yang et al. (2000). Codon-substitution models for heterogeneous selection pressure at amino acid sites. Genetics, 155(1):431-49.

Yeates, D.K. (1992). Towards a monophyletic Bombyliidae (Diptera): the removal of the Proratinae (Diptera: Scenopinidae). Am. Mus. Novit., 3051:1-30.

Yeates, D.K. (1994). Cladistics and classification of the Bombyliidae (Diptera: Asiloidea). Bull. Am. Mus. Nat. Hist., 219:1-191.

Yeates, D.K. and Irwin, M.E. (1996). Apioceridae (Insecta: Diptera): cladistic reappraisal and biogeography. Zool. J. Linn. Soc. 116:247-301.

Yeates, D.K. and Wiegmann, B.M. (1999). Congruence and Controversy: Toward a Higher - Level Classification of Diptera. Annual Rev. Entomol., 44: 397-428. 
Sara A. Al-Ashaal et al.

Yeates, D.K. (2002). Relationships of the lower Brachycera (Diptera): A quantitative synthesis of morphological characters. Zoologica Scripta, 31: 105-121.

Yeates, D.K.; Wiegmann, B.M.; Courtney, G.W.; Meier, R.; Lampkin, C. and Pape, T. (2007). Phylogeny and

systematics of Diptera: Two decades of progress and prospects, Zootaxa 1668: 565-59.

Zatwarnicki, T. (1996). A new reconstruction of the origin of the eremoneuran hypopygium and its implications for classification. Genus, $\quad$ 7:103-175.

\section{Appendix 1}

List of the species and its code included in the analysis.

\begin{tabular}{|c|c|c|c|}
\hline Species & Code & Species & Code \\
\hline $\begin{array}{l}\text { F: Asilidae } \\
\text { Sub. F.: Apocleinae } \\
\text { 1- Apoclea femoralis (Macquart, 1828) }\end{array}$ & $\mathbf{a}$ & $\begin{array}{l}\text { F: Muscidae } \\
\text { Sub. F.: Atherigoninae } \\
\text { 15- Atherigona atherigona laevigata (Loew, 1852) }\end{array}$ & $\mathbf{0}$ \\
\hline $\begin{array}{l}\text { Sub. F.: Dasypogoninae } \\
\text { 2- Saropogon longicornis (Macquart, 1838) }\end{array}$ & $\mathbf{b}$ & 16- Atherigona orientalis (Schiner, 1868) & $\mathbf{p}$ \\
\hline $\begin{array}{l}\text { F: Therevidae } \\
\text { Sub. F.: Phycinae } \\
\text { 3- Ruppellia thoracica (Macquart, 1840) }\end{array}$ & c & $\begin{array}{l}\text { Sub. F.: Muscinae } \\
\text { 17- Musca domestica (Linnaeus, 1758) }\end{array}$ & $\mathbf{q}$ \\
\hline 4- Ruppellia semiflava (Wiedemann, 1830) & d & $\begin{array}{l}\text { F: Fanniidae } \\
\text { 18- Fannia canicularis (Linnaeus, 1761) }\end{array}$ & $\mathbf{r}$ \\
\hline $\begin{array}{l}\text { Sub. F.: Therevinae } \\
\text { 5- Thereva sp. }\end{array}$ & e & $\begin{array}{l}\text { F: Stratiomyidae } \\
\text { Sub. F.: Stratiomyinae } \\
\text { 19- Stratiomys anubis (Wiedemann, 1830) }\end{array}$ & $\mathbf{s}$ \\
\hline $\begin{array}{l}\text { F: Bombyliidae } \\
\text { Sub. F.: Bombyliinae } \\
\text { 6- Bombylius numidus (Macquart, 1846) }\end{array}$ & $\mathbf{f}$ & 20- Stratiomys longicornis (Scopoli, 1763) & $\mathbf{t}$ \\
\hline $\begin{array}{l}\text { Sub. F.: Anthracinae } \\
\text { 7- Anthrax incitus Paramonov, } 1935\end{array}$ & $\mathbf{g}$ & $\begin{array}{l}\text { Sub. F.: Nemotelinae } \\
21-\text { Nemotelus niloticus (Olivier, 1811) }\end{array}$ & $\mathbf{u}$ \\
\hline $\begin{array}{l}\text { F: Phoridae } \\
\text { Sub. F.: Metopininae } \\
\text { 8- Megaselia scalaris (Loew, 1866) }\end{array}$ & $\mathbf{h}$ & 22- Nemotelus albifacies Becker, 1902 & $\mathbf{v}$ \\
\hline $\begin{array}{l}\text { F: Syrphidae } \\
\text { Sub. F.: Syrphinae } \\
\text { 9- Eupeodes eupeodes corollae (Fabricius, 1794) }\end{array}$ & $\mathbf{i}$ & 23-Nemotelus oasis Becker, 1906 & $\mathbf{w}$ \\
\hline $\begin{array}{l}\text { Sub. F.: Eristalinae } \\
\text { 10- Eristalinus eristalodes taeniops (Wiedemann, } \\
1818 \text { ) }\end{array}$ & g & $\begin{array}{l}\text { F: Tabanidae } \\
\text { Sub. F.: Tabaninae } \\
\text { 24- Tabanus taeniola (Palisot de Beauvois, 1806) }\end{array}$ & $\mathbf{x}$ \\
\hline $\begin{array}{l}\text { F: Tephritidae } \\
\text { Sub. F.: Tephritinae } \\
\text { 11- Paradesis augur (Frauenfeld, 1857) }\end{array}$ & $\mathbf{k}$ & 25- Atylotus agrestis (Wiedemann, 1828) & $\mathbf{y}$ \\
\hline $\begin{array}{l}\text { Dacinae } \\
\text { 12- Dacus longistylus (Wiedemann, 1830) }\end{array}$ & l & $\begin{array}{l}\text { F: Vermileonidae } \\
\text { 26-Vermileo vermileo (Linnaeus, 1758) }\end{array}$ & $\mathbf{Z}$ \\
\hline $\begin{array}{l}\text { F: Sarcophagidae } \\
\text { Sub. F.: Paramacronychiinae } \\
\text { 13- Wohlfahrtia nuba ((Wiedemann, 1830) }\end{array}$ & $\mathbf{m}$ & $\begin{array}{l}\text { Nematocera } \\
\text { F: Culicidae } \\
\text { Sub. F.: Culicinae } \\
\text { 27- Culex pipiens (Linnaeus, 1758) }\end{array}$ & $\mathbf{I}$ \\
\hline $\begin{array}{l}\text { Sub. F.: Sarcophaginae } \\
\text { 14- Sarcophaga aegyptica (Salem, 1935) }\end{array}$ & $\mathbf{n}$ & & \\
\hline
\end{tabular}




\section{Phylogeny of the Basal Lineages of Suborder Brachycera (Diptera) in Egypt}

\section{Appendix 2 \\ Characters and character states.}

- Adult body: 1. Body length in male: $(0)=$ shorter than $17.5 \mathrm{~mm}$ [b-z, I], (1) = longer than $17.5 \mathrm{~mm}$ [a].

2. Body length in female: $(0)=$ shorter than $16.5 \mathrm{~mm}[\mathbf{b}-\mathbf{w}, \mathbf{y}, \mathbf{z}, \mathbf{I}],(1)=$ longer than $16.5 \mathrm{~mm}[\mathbf{a}, \mathbf{x}]$.

3. Body shape: $(0)=$ not bee like[a-e, h, k-r, u-w, , z, I], (1) = bee like [f, $\mathbf{g}, \mathbf{i}, \mathbf{j}, \mathbf{s}, \mathbf{t}, \mathbf{x}]$.

- Adult-Head: 4. Head: (0) = narrower than thorax [f, g], (1) = equal to thorax [a-e, h, k-w, z, I], (2) = broader than the widest part of thorax $[\mathbf{i}, \mathbf{j}, \mathbf{x}, \mathbf{y}]$.

5. Width of head: $(0)=$ less than twice length of head [c-e, $\mathbf{g - l}, \mathbf{o - r}, \mathbf{u}-\mathbf{y}, \mathbf{I}],(1)=$ equal to or more than twice length of head $[\mathbf{a}, \mathbf{b}, \mathbf{f}, \mathbf{m}, \mathbf{n}, \mathbf{s}, \mathbf{t}, \mathbf{z}]$.

6. Length of head: $(0)=$ less than half highest of head $[\mathbf{h}, \mathbf{l}, \mathbf{o - r}, \mathbf{z}, \mathbf{I}],(1)=$ more than or equal to half highest of head [a-g, i-k, m, n, s-y].

7. Highest of head: $(0)=$ less than half width of head $[1, \mathrm{o}-\mathrm{r}, \mathrm{z}, \mathrm{I}],(1)=$ more than or equal to half width of head [a-k, m, n, s-y].

8. Head in profile: $(0)=$ quadrangular $[\mathbf{o}, \mathbf{p}],(1)=$ hemispherical $[\mathbf{a}, \mathbf{b}, \mathbf{f}-\mathbf{j}, \mathbf{q}-\mathbf{t}],(2)=$ spherical $[\mathbf{c}-\mathbf{e}, \mathbf{z}]$

(3) = semi quadrate [k-n, $\mathbf{x}, \mathbf{y}],(4)=$ triangular [u-w], (5) = sub-globose [I] .

9. Vertex: $(0)=$ semi concave $[\mathbf{x}-\mathbf{z}, \mathbf{I}],(1)=$ flat $[\mathbf{c}-\mathbf{w}],(2)=$ convex $[\mathbf{a}, \mathbf{b}]$.

- Eye: 10. Eyes: $(0)=$ bare $[\mathbf{a}-\mathbf{h}, \mathbf{k}-\mathbf{r}, \mathbf{u}-\mathbf{z}, \mathbf{I}],(1)=$ with pubescence $[\mathbf{i}, \mathbf{j}, \mathbf{s}, \mathbf{t}]$.

11. Eyes' markings in dried specimens in male: $(0)=$ without markings $[\mathbf{a}-\mathbf{i}, \mathbf{k}-\mathbf{w}, \mathbf{y}, \mathbf{x}, \mathbf{I}],(1)=$ with markings [j, $\mathbf{x}]$.

12. Eyes' markings in dried specimens in female: $(0)=$ without markings $[\mathbf{a}-\mathbf{i}, \mathbf{k}-\mathbf{z}, \mathbf{I}],(1)=$ with markings $[\mathbf{j}]$.

13. Eyes with markings in male: $(0)=$ with transverse stripes $[\mathbf{j}, \mathbf{x}],(1)=$ with spots $[-]$.

14. Eyes with markings in female: $(0)=$ with transverse stripes $[\mathbf{j}],(1)=$ with spots $[-]$.

15. Eyes in male: (0) = contiguous $[\mathbf{c}-\mathbf{f}, \mathbf{i}, \mathbf{j}, \mathbf{s}-\mathbf{y}],(1)=\operatorname{dichoptic}[\mathbf{a}, \mathbf{b}, \mathbf{g}, \mathbf{h}, \mathbf{k}-\mathbf{p}, \mathbf{z}],(2)=$ semi-contiguous

$[\mathbf{q}, \mathbf{r}, \mathbf{I}]$.

16. Eyes semi-contigous in female: $(0)=$ absent $[\mathbf{a}-\mathbf{z}],(1)=$ present $[\mathbf{I}]$.

17. Ocelli: $(0)=$ absent $[\mathbf{x}, \mathbf{y}, \mathbf{I}],(1)=$ not located on ocellar tubercle $[\mathbf{c}-\mathbf{h}, \mathbf{k}-\mathbf{r}, \mathbf{z}],(2)=$ located on ocellar tubercle [a, b, i, j, s-w].

18. Frontal suture: $(0)=$ absent $[\mathbf{a}-\mathbf{j}, \mathbf{s - z}, \mathbf{I}],(1)=$ present $[\mathbf{k}-\mathbf{r}]$.

19. The lunule: $(0)=$ absent $[\mathbf{a}-\mathbf{j}, \mathbf{s}-\mathbf{z}, \mathbf{I}],(1)=$ present $[\mathbf{k}-\mathbf{r}]$.

20. Face: $(0)=$ flat to slightly prominent $[\mathbf{a}-\mathbf{h}, \mathbf{k}-\mathbf{r}, \mathbf{x}-\mathbf{z}, \mathbf{I}],(1)=$ with short facial projection $[\mathbf{i}, \mathbf{j}],(2)=$ with moderate facial projection $[\mathbf{s}, \mathbf{t}],(3)=$ with long facial projection $[\mathbf{u}-\mathbf{w}]$.

21. Clypeus appear as a small sclerite U-shaped: $(0)=$ absent $[\mathbf{a}-\mathbf{g}, \mathbf{s - z}, \mathbf{I}],(1)=$ present $[\mathbf{h}-\mathbf{r}]$.

22. Ocellar bristles: $(0)=$ absent $[\mathbf{c}-\mathbf{g}, \mathbf{i}, \mathbf{j}, \mathbf{s - z}, \mathbf{I}],(1)=\operatorname{divergent}[\mathbf{o}, \mathbf{p}],(2)=$ convergent $[\mathbf{a}, \mathbf{b}, \mathbf{h}, \mathbf{k}-\mathbf{n}, \mathbf{q}, \mathbf{r}]$.

23. Inner vertical bristles: (0) = absent [a-g, i, j, s-z, I], (1) = divergent [1, o-r], (2) = convergent [k, $\mathbf{m}, \mathbf{n}]$,

(3) = parallel $[\mathbf{h}]$.

24. Outer vertical bristles: (0) = absent $[\mathbf{a}-\mathbf{g}, \mathbf{i}, \mathbf{j}, \mathbf{s - z}, \mathbf{I}],(1)=$ divergent $[\mathbf{h}, \mathbf{k}-\mathbf{m}],(2)=$ parallel $[\mathbf{n}-\mathbf{r}]$.

25. Postocellar bristles: $(0)=$ absent $[\mathbf{c}-\mathbf{e}, \mathbf{i}, \mathbf{j}, \mathbf{s}-\mathbf{z}, \mathbf{I}],(1)=$ divergent $[\mathbf{h}, \mathbf{k}-\mathbf{r}],(2)=$ convergent $[\mathbf{a}, \mathbf{b}, \mathbf{f}, \mathbf{g}]$.

26. Postvertical bristles: $(0)=$ absent $[\mathbf{a}-\mathbf{g}, \mathbf{i}, \mathbf{j}, \mathbf{s - z}, \mathbf{I}],(1)=$ divergent $[\mathbf{m}-\mathbf{r}],(2)=$ parallel $[\mathbf{h}, \mathbf{k}, \mathbf{l}]$.

27. Frons differentiated into frontal vitta and lateral fronto-orbital plates: $(0)=$ absent $[\mathbf{a}-\mathbf{j}, \mathbf{s}-\mathbf{z}, \mathbf{I}],(1)=$ present [k-r].

28. Width of frons in female: $(0)=$ less than half width of head [a-g, o-z], (1) = equal to half width of head $[\mathbf{I}],(2)=$ more than half width of head $[\mathbf{h}-\mathbf{n}]$.

29. Width of frons in male: $(0)=$ less than $1 / 4$ width of head $[\mathbf{q}, \mathbf{r}, \mathbf{I}],(1)=$ more than $1 / 4$ width of head [a-p, s-z].

30. Frontal index in female: $(0)=$ less than $2[\mathbf{a}-\mathbf{w}, \mathbf{z}, \mathbf{I}],(1)=$ more than $2[\mathbf{x}, \mathbf{y}]$.

31. Frons in female: $(0)=$ without calli $[\mathbf{a}-\mathbf{w}, \mathbf{z}, \mathbf{I}],(1)=$ with two calli $[\mathbf{y}],(2)=$ with three calli $[\mathbf{x}]$.

32. Orbital bristles reclinate: $(0)=$ absent $[\mathbf{c}-\mathbf{g}, \mathbf{i}, \mathbf{j}, \mathbf{s - z}, \mathbf{I}],(1)=$ divergent $[\mathbf{a}, \mathbf{b}],(2)=$ convergent $[\mathbf{h}, \mathbf{k}-\mathbf{r}]$.

33. Orbital bristles proclinate in female: $(0)=$ absent $[\mathbf{c}-\mathbf{g}, \mathbf{i}, \mathbf{j}, \mathbf{s - z}, \mathbf{I}],(1)=\operatorname{divergent}[\mathbf{a}, \mathbf{b}],(2)=$ convergent [h, k-r].

34. Anterior frontal bristles: $(0)=$ absent $[\mathbf{a}-\mathbf{g}, \mathbf{i}, \mathbf{j}, \mathbf{s - z}, \mathbf{I}],(1)=$ present $[\mathbf{h}, \mathbf{k}-\mathbf{r}]$. 


\section{Sara A. Al-Ashaal et al.}

35. Interfrontal bristles: $(0)=$ absent $[\mathbf{a}-\mathbf{g}, \mathbf{i}, \mathbf{j}, \mathbf{s - z}, \mathbf{I}],(1)=$ present $[\mathbf{h}, \mathbf{k}-\mathbf{r}]$.

36. mystax: $(0)=$ absent $[\mathbf{c}-\mathbf{z}, \mathbf{I}],(1)=$ present $[\mathbf{a}, \mathbf{b}]$.

37. Vibrissae: $(0)=$ absent $[\mathbf{a}-\mathbf{g}, \mathbf{i}, \mathbf{j}, \mathbf{s - z}, \mathbf{I}],(1)=$ present $[\mathbf{h}, \mathbf{k}-\mathbf{r}]$.

38. Occiput developed into two lateral swelling: $(0)=$ absent $[\mathbf{a}-\mathbf{j}, \mathbf{m}-\mathbf{z}, \mathbf{I}],(1)=$ present $[\mathbf{k}, \mathbf{l}]$.

- Antennae: 39. Antennae: $(0)=$ not the same in both sexes [I],$(1)=$ the same in both sexes [a-z].

40. Type of antennae: $(0)=$ Pilose (female) or plumose (male) [I],$(1)=$ Stylate $[\mathbf{a}-\mathbf{g}, \mathbf{u}-\mathbf{z}],(2)=$ Aristate $[\mathbf{h}-$ $\mathbf{r}],(3)=$ Geniculate $[\mathbf{s}, \mathbf{t}]$.

41- Shape of scape: $(0)=$ short slender [a-e, g, k-r, t-v], (1)=elongate selnder [s, t $],(2)=$ cup-shape $[\mathbf{i}, \mathbf{j}, \mathbf{x}-$ $\mathbf{z}],(3)=$ swollen [f, $\mathbf{h}, \mathbf{I}]$.

42. Scape: $(0)=$ short, length equal to or less than three the pedicel length $[\mathbf{a}-\mathbf{e}, \mathbf{h}-\mathbf{r}, \mathbf{u}-\mathbf{z}, \mathbf{I}],(1)=$ elongate, length more than three the pedicel length $[\mathbf{f}, \mathbf{g}, \mathbf{s}, \mathbf{t}]$.

43. Shape of pedicel: $(0)=$ nearly square $[\mathbf{c}-\mathbf{g}],(1)=$ slender $[\mathbf{a}, \mathbf{b}, \mathbf{k}-\mathbf{w}, \mathbf{z}, \mathbf{I}],(2)=$ spherical $[\mathbf{h}-\mathbf{j}],(3)=$ cup-shape $[\mathbf{x}, \mathbf{y}]$.

44. Pedicel: $(0)=$ without seam $[\mathbf{a}-\mathbf{l}, \mathbf{s - z}, \mathbf{I}],(1)=$ with dorsal seam $[\mathbf{m}-\mathbf{r}]$.

45. Proportion between lengths of antennae to length of flagellum: $(0)=$ length of antennae less than 2 times length of flagellum [c-e, $\mathbf{x}-\mathbf{z}],(1)=$ length of antennae more than 2 times length of flagellum [a, $\mathbf{b}$, f-w, I].

46. Length of antennal flagellum: $(0)=$ less than or equal to length of basal antennal segments [s-z, I], (1)

$=$ more than length of basal antennal segments [a-r].

47. Proportion between widths of basal flagellomere to half width of scape: $(0)=$ less than or equal to half width of scape $[\mathbf{u}-\mathbf{w}, \mathbf{z}],(1)=$ more than half width of scape $[\mathbf{a}-\mathbf{t}, \mathbf{x}, \mathbf{y}, \mathbf{I}]$.

48. Width of basal flagellomere: $(0)=$ less than or nearly equal to $1 / 4$ length of flagellum [a-e, g-r], $(1)=$ more than 1/4 length of flagellum [f, s-z, I].

49. Length of style: $(0)=$ less than or equal to $1 / 4$ length of antennae $[\mathbf{b}-\mathbf{g}, \mathbf{s}-\mathbf{w}, \mathbf{z}],(1)=$ more than $1 / 4$ length of antennae $[\mathbf{a}, \mathbf{x}, \mathbf{y}]$.

50. Length of arista: $(0)=$ less than or equal to 3 times length of antennae [i-r], $(1)=$ more than 3 times length of antennae $[\mathbf{h}]$.

51. Proportion between lengths of style to length of flagellum: $(0)=$ length of style less than or equal to 1/4 length of flagellum [a-g, s-w, z], (1) = length of style more than 1/4 length of flagellum [x, $\mathbf{y}]$.

52. Annulations of flagellum: $(0)=$ not annulated $[\mathbf{f}, \mathbf{h}-\mathbf{r}],(1)=$ annulated $[\mathbf{a}-\mathbf{e}, \mathbf{g}, \mathbf{s - z}, \mathbf{I}]$.

53. Flagellum: $(0)=$ with arista $[\mathbf{h}-\mathbf{r}, \mathbf{I}],(1)=$ with stylus $[\mathbf{a - g}, \mathbf{s - z}]$.

54. Number of flagellum segments: $(0)=$ two $[\mathbf{a}, \mathbf{f}, \mathbf{z}],(1)=$ three $[\mathbf{b}-\mathbf{e}, \mathbf{y}],(2)=$ four $[\mathbf{g}],(3)=$ five $[\mathbf{t}, \mathbf{x}]$, (4) $=\operatorname{six}[\mathbf{s}, \mathbf{u}-\mathbf{w}]$.

55. Arista insertion: (0) dorso-basally [i-r], (1) apically [h].

56. Arista segmented: $(0)=$ absent $[\mathbf{i}-\mathbf{r}],(1)=$ present $[\mathbf{h}]$.

57. Arista: $(0)=$ not plumose $[\mathbf{h}-\mathbf{m}, \mathbf{o}-\mathbf{r}],(1)=$ plumose $[\mathbf{n}]$.

58. Arista plumose on the basal part and bare on the distal: $(0)=$ not plumose on the basal part and bare on the distal [h-m, o-r],

$(1)=$ plumose on the basal part and bare on the distal $[\mathbf{n}]$.

- Mouthparts: 59. Mouth part: (0) = shorter than head [a-e, g-t, x-z], (1) = longer than head [f, u-w, I].

60. Mouth parts: $(0)=$ piercing sucking in female and sucking in male $[\mathbf{f}, \mathbf{x}, \mathbf{y}, \mathbf{I}],(1)=$ sponging $[\mathbf{c}-\mathbf{e}, \mathbf{g}-\mathbf{w}$, $\mathbf{z}],(2)=$ raptorial $[\mathbf{a}, \mathbf{b}]$.

61. Proboscis as long as or longer than fore femur usually longer: $(0)=$ absent [a-e, g-z], (1)=present [f, I] . 62. Labrum: $(0)=$ simple [a-e, $\mathbf{g - w}, \mathbf{z}],(1)=$ modified for piercing, with a pair of apical epipharyngeal blades [f, $\mathbf{x}, \mathbf{y}, \mathbf{I}]$.

63. Lacinia: $(0)=$ blunt apically $[\mathbf{a - e}, \mathbf{g - w}],(1)=$ blade-like $[\mathbf{f}, \mathbf{x}, \mathbf{y}, \mathbf{I}]$.

64. Maxillary palp: $(0)=$ one segment $[\mathbf{c}-\mathbf{e}, \mathbf{h}-\mathbf{w}],(1)=$ two segments $[\mathbf{a}, \mathbf{b}, \mathbf{f}, \mathbf{g}, \mathbf{x}, \mathbf{y}],(2)=$ more than two segments [I]

65. Mandible: $(0)=$ vestigial or absent $[\mathbf{a - e}, \mathbf{g}-\mathbf{w}],(1)=\operatorname{present}[\mathbf{f}, \mathbf{x}, \mathbf{y}, \mathbf{I}]$.

66. Mandible stylets in female: $(0)=$ short blades [f], $(1)=$ long, slender and have the medial margin finely serrated $[\mathbf{x}, \mathbf{y}, \mathbf{I}]$. 


\section{Phylogeny of the Basal Lineages of Suborder Brachycera (Diptera) in Egypt}

67. Maxillae: $(0)=$ vestigial [a-e, $\mathbf{g - w}],(1)=\operatorname{present}[\mathbf{f}, \mathbf{x}, \mathbf{y}, \mathbf{I}]$.

68. Maxillary stylets in female: $(0)=$ short blades $[\mathbf{f}, \mathbf{x}, \mathbf{y}],(1)=$ long, shaped as serrated blade in the distal [I].

69. Pseudotracheae: $(0)=$ absent $[\mathbf{a}, \mathbf{b}, \mathbf{f}, \mathbf{I}],(1)=\operatorname{present}[\mathbf{c}-\mathbf{e}, \mathbf{g}-\mathbf{y}]$.

70. Epipharynx stylet-shaped: $(0)=$ absent $[\mathbf{c}-\mathbf{w}],(1)=$ present $[\mathbf{a}, \mathbf{b}, \mathbf{x}, \mathbf{y}, \mathbf{I}]$.

71. Epipharynx: $(0)=$ membranous $[\mathbf{c}-\mathbf{w}],(1)=$ more or less sclerotized $[\mathbf{a}, \mathbf{b}, \mathbf{x}, \mathbf{y}, \mathbf{I}]$.

72. Labium: $(0)=$ short $[\mathbf{a}-\mathbf{z}],(1)=$ elongated and terminate with two small labella $[\mathbf{I}]$.

- Adult-Thorax:

- Prothorax: 73. The antepronotum: $(0)=$ poorly developed [a-z], $(1)=$ well developed [I].

74. The postpronotum: $(0)=$ poorly developed [I],$(1)=$ well developed $[\mathbf{a}-\mathbf{z}]$.

- Mesothorax: 75. Thorax: $(0)=$ not striped [g-l, r-w, I], (1) = with two stripes [a-e], (2) = with three stripes $[\mathbf{f}, \mathbf{y}, \mathbf{z}],(3)=$ with four

stripes $[\mathbf{q}, \mathbf{x}],(4)=$ with five stripes $[\mathbf{m}, \mathbf{n}],(5)=$ with sixo stripes $[\mathbf{o}, \mathbf{p}]$.

76. Width of thorax: $(0)=$ less than $3 / 4$ width of head $[\mathbf{a}-\mathbf{g}, \mathbf{k}-\mathbf{w}, \mathbf{z}, \mathbf{I}],(1)=$ equal to more than $3 / 4$ width of head $[\mathbf{h}-\mathbf{j}, \mathbf{x}, \mathbf{y}]$.

77. Thorax shape: $(0)=$ not humped $[\mathbf{a - g}, \mathbf{i}-\mathbf{z}, \mathbf{I}],(1)=$ humped $[\mathbf{h}]$.

78. Thorax with transverse suture: $(0)=$ absent $[\mathbf{h}-\mathbf{l}, \mathbf{z}, \mathbf{I}],(1)=$ present $[\mathbf{a}-\mathbf{g}, \mathbf{m}-\mathbf{y}]$.

79. Greater ampullae: $(0)=$ absent $[\mathbf{a}-\mathbf{l}, \mathbf{s}-\mathbf{z}, \mathbf{I}],(1)=$ present $[\mathbf{m}-\mathbf{r}]$.

80. Postpronotal (humeral) setae: $(0)=$ absent $[\mathbf{c}-\mathbf{j}, \mathbf{l}, \mathbf{s - z}, \mathbf{I}],(1)=$ present $[\mathbf{a}, \mathbf{b}, \mathbf{k}, \mathbf{m}-\mathbf{r}]$.

81. Proepisternum (propleuron) dorsally: $(0)=$ bare $[\mathbf{c}-\mathbf{e}, \mathbf{i}-\mathbf{p}, \mathbf{r}-\mathbf{z}, \mathbf{I}],(1)=\operatorname{setose}[\mathbf{a}, \mathbf{b}, \mathbf{f}-\mathbf{h}, \mathbf{q}]$.

82. Precoxal bridge: $(0)=$ absent $[\mathbf{h}-\mathbf{r}, \mathbf{x}-\mathbf{z}, \mathbf{I}],(1)=$ present $[\mathbf{a - g}, \mathbf{s}-\mathbf{w}]$.

83. Hypopleuron: $(0)=$ without bristles $[\mathbf{b}-\mathbf{l}, \mathbf{0}-\mathbf{z}, \mathbf{I}],(1)=$ with bristles $[\mathbf{a}, \mathbf{m}, \mathbf{n}]$.

84. Scutum, acrostichal bristles: $(0)=$ absent $[\mathbf{c}-\mathbf{j}, \mathbf{l}, \mathbf{s - z}, \mathbf{I}],(1)=$ present $[\mathbf{a}, \mathbf{b}, \mathbf{k}, \mathbf{m}-\mathbf{r}]$.

85. Supra-alar bristles: $(0)=$ absent $[\mathbf{f}, \mathbf{g}, \mathbf{i}, \mathbf{j}, \mathbf{s}-\mathbf{z}, \mathbf{I}],(1)=$ present $[\mathbf{a}-\mathbf{e}, \mathbf{h}, \mathbf{k}-\mathbf{r}]$.

86. Post-alar bristles: $(0)=$ absent $[\mathbf{h}-\mathbf{l}, \mathbf{s}-\mathbf{z}, \mathbf{I}],(1)=$ present $[\mathbf{a}-\mathbf{g}, \mathbf{m}-\mathbf{r}]$.

87. Dorsocentral bristles: $(0)=$ absent $[\mathbf{f}-\mathbf{j}, \mathbf{l}, \mathbf{s - z}, \mathbf{I}],(1)=$ present $[\mathbf{a}-\mathbf{e}, \mathbf{k}, \mathbf{m}-\mathbf{r}]$.

88. Posterior anepisternal bristles: $(0)=$ absent $[\mathbf{b}-\mathbf{f}, \mathbf{h}-\mathbf{l}, \mathbf{o}, \mathbf{p}, \mathbf{s - z}, \mathbf{I}],(1)=$ present $[\mathbf{a}, \mathbf{g}, \mathbf{m}, \mathbf{n}, \mathbf{q}, \mathbf{r}]$.

89. Katepisternal bristles: (0) = absent $[\mathbf{a}-\mathbf{l}, \mathbf{o}, \mathbf{p}, \mathbf{s - z}, \mathbf{I}],(1)=\operatorname{present}[\mathbf{m}, \mathbf{n}, \mathbf{q}, \mathbf{r}]$.

90. Anepimeral bristles: $(0)=$ absent $[\mathbf{b}-\mathbf{p}, \mathbf{s - z}, \mathbf{I}],(1)=\operatorname{present}[\mathbf{a}, \mathbf{q}, \mathbf{r}]$.

91. Notopleural bristles: (0) = absent $[\mathbf{b}, \mathbf{i}, \mathbf{j}, \mathbf{l}, \mathbf{s - z}, \mathbf{I}],(1)=$ two or more $[\mathbf{a}, \mathbf{c}-\mathbf{h}, \mathbf{k}, \mathbf{m}-\mathbf{r}]$.

92. Postalar wall: $(0)=$ absent $[\mathbf{h}, \mathbf{i}, \mathbf{I}],(1)=$ present $[\mathbf{a}-\mathbf{g}, \mathbf{j}-\mathbf{z}]$.

93. Scutellar bristles: $(0)=$ absent $[\mathbf{i}, \mathbf{j}, \mathbf{s - z}, \mathbf{I}],(1)=$ present $[\mathbf{a}-\mathbf{h}, \mathbf{k}-\mathbf{r}]$.

94. Scutellar bristles lateroscutellar: $(0)=$ absent $[\mathbf{a}-\mathbf{e}, \mathbf{h}],(1)=$ one pair $[\mathbf{f}, \mathbf{g}, \mathbf{k}, \mathbf{l}],(2)=$ two pairs [m-r].

95. Scutellar bristles apicoscutellar: $(0)=$ absent $[-],(1)=$ present [a-h, k-r].

96. Scutellar bristles discoscutellar: (0)= absent [c-e,h], (1)=one pair [a, b, k, l], (2)=two pairs [f, g, m-r].

97. Upper calypter: (0) = not developed [h, $\mathbf{k}, \mathbf{l}, \mathbf{z}, \mathbf{I}],(1)=$ bare $[\mathbf{a}-\mathbf{e}, \mathbf{m}-\mathbf{r}, \mathbf{x}, \mathbf{y}],(2)=$ setose $[\mathbf{f}, \mathbf{g}, \mathbf{i}, \mathbf{j}, \mathbf{s}-\mathbf{w}]$.

98. Lower calypter: (0)=slightly developed [a-e, h,k, l,z,I], (1)=bare [m-r, x, y], (2)=setose [f,g, i, j, s-w].

99. Meron: $(0)=$ small, triangular sclerite $[\mathbf{h}-\mathbf{r}],(1)=$ large, round, as fully developed behind midcoxa as katepisternum is in front of

midcoxa [a-g, s-z, I].

100. Vertical row of setae on meron: $(0)=$ absent $[\mathbf{a}-\mathbf{l}, \mathbf{o - z}, \mathbf{I}],(1)=$ present $[\mathbf{m}, \mathbf{n}]$.

101. Wing: $(0)=$ without maculae $[\mathbf{a}-\mathbf{k}, \mathbf{m}-\mathbf{z}, \mathbf{I}],(1)=$ with maculae [I].

102. Dark spots at the tip of the wing: $(0)=$ absent $[\mathbf{a}-\mathbf{j}, \mathbf{l}-\mathbf{z}, \mathbf{I}],(1)=$ present $[\mathbf{k}]$.

103. Wing with scales: $(0)=$ absent $[\mathbf{a}-\mathbf{z}],(1)=$ present $[\mathbf{I}]$.

104. Costa: $(0)=$ circumambient, continuous around the wing, weakened along the posterior margin [a, e$\mathbf{g}, \mathbf{x - z}, \mathbf{I}]$,

(1) = abbreviated, ending at or before $\mathbf{M}_{2}$. $[\mathbf{b}-\mathbf{d}, \mathbf{h}-\mathbf{w}]$.

105. Humeral break: $(0)=$ absent $[\mathbf{a}-\mathbf{j}, \mathbf{m}-\mathbf{z}, \mathbf{I}],(1)=\operatorname{present}[\mathbf{k}, \mathbf{l}]$.

106. Rs origin: $(0)=$ opposite or very near humeral crossvein $[\mathbf{c}-\mathbf{e}, \mathbf{g}, \mathbf{h}, \mathbf{j}$-w], $(1)=$ distal, distant from humeral [a, b, f, i, x-z, I].

107. Rs: $(0)=$ two-branched $[\mathbf{f}-\mathbf{r}, \mathbf{u}-\mathbf{z}],(1)=$ three-branched $[\mathrm{a}-\mathrm{e}, \mathrm{s}, \mathrm{t}, \mathrm{I}]$. 


\section{Sara A. Al-Ashaal et al.}

108. Radial vein distribution: $(0)=$ evenly distributed $[\mathbf{a}-\mathbf{r}, \mathbf{x}-\mathbf{z}, \mathbf{I}],(1)=$ crowded towards costal margin, $\mathrm{R}_{5}$ ending before wing apex [s-w].

109. Wing vein $R_{2:}(0)=\operatorname{absent}[\mathbf{a}-\mathbf{z}],(1)=$ present [ $\left.\mathbf{I}\right]$.

110. $R_{2}$ at least as long as vein $R_{2+3}:(0)=$ absent [a-z], $(1)=$ present [I] .

111. Subcosta intersects costa at or beyond level of furcation of $R_{2+3:}(0)=\operatorname{absent}[\mathbf{a}-\mathbf{z}],(1)=$ present [I] .

112. Wing vein $R_{3:}(0)=$ absent [a-z], (1) = present [I] .

113. Wing vein $\mathbf{R}_{2+3:}(0)=$ absent $[\mathbf{I}],(1)=$ ending near wing apex [a-f, $\left.\mathbf{i}-\mathbf{s}, \mathbf{x}-\mathbf{z}\right],(2)=$ ending near $\mathbf{R}_{1}[\mathbf{g}$, h, t-w].

114. $\mathbf{R}_{1}+\mathrm{R}_{2}+\mathrm{R}_{3}$ united: $(0)=$ absent $[\mathbf{a}-\mathbf{t}, \mathbf{x}-\mathbf{z}, \mathbf{I}],(1)=$ present $[\mathbf{u}-\mathbf{w}]$.

115. $\mathrm{R}_{2+3}$ in the middle between $\mathrm{r}_{1}$ and apex: $(0)=$ absent $[\mathbf{a}, \mathbf{b}, \mathbf{f - z}],(1)=$ present [c-e].

116. Wing vein $\mathrm{R}_{4+5}:(0)=$ unbranched or fused [g-r, I], (1) = branched [a-f, s-z].

117. Fork of wing vein $R_{4+5}$ : $(0)=$ not strongly divergent, ending either above or below wing tip [a-g,s-w],

(1) = strongly divergent, encompassing wing tip, such that $R_{5}$ is much closer to $M_{1}$ than $R_{4}[\mathbf{x}, \mathbf{y}]$.

118. Vein M: $(0)=$ not upcurved at fork of discal cell or at junction with crossvein $\mathbf{r}-\mathbf{m}[\mathbf{h}, \mathbf{k}-\mathbf{r}],(1)=$ upcurved at fork of discal

cell or at junction with crossvein r-m [a-g, I, j, s-z, I]

119. $\mathbf{M}_{2}$ jointed with $\mathrm{M}_{3}:(0)=$ absent $[\mathbf{b}-\mathbf{g}, \mathbf{s - z}],(1)=$ present $[\mathbf{a}, \mathbf{h}-\mathbf{r}, \mathbf{I}]$.

120. $\mathbf{M}_{1}$ jointed with $\mathrm{R}_{5}:(0)=$ absent $[\mathbf{a}-\mathbf{e}, \mathbf{s - z}],(1)=\operatorname{present}[\mathbf{f}, \mathbf{g}]$.

121. $\mathbf{M}_{1+2}$ jointed with $\mathbf{R}_{4+5}$ : $(0)=\operatorname{absent}[\mathbf{m}-\mathbf{r}],(1)=\operatorname{present}[\mathbf{i}, \mathbf{j}]$.

122. Vein $\mathbf{M}_{2}:(0)=$ not reaching wing margine [b-g, $\left.\mathbf{s - z}\right],(1)=$ reaching wing margine [-].

123. $\mathrm{M}_{1}$ fused with CuA: (0) = absent $[\mathbf{f}-\mathbf{h}, \mathbf{j}, \mathbf{s - y}, \mathbf{I}],(1)=$ present $[\mathbf{a}-\mathbf{e}, \mathbf{i}, \mathbf{k}-\mathbf{r}, \mathbf{z}]$.

124. Discal or discal medial: $(0)=$ absent $[\mathbf{h}, \mathbf{I}],(1)=$ present $[\mathbf{a}-\mathbf{g}, \mathbf{i}-\mathbf{z}]$.

125. Discal cell: $(0)=$ hexagonal $[\mathbf{s}-\mathbf{w}],(1)=$ semi-triangular $[\mathbf{a}-\mathbf{r}, \mathbf{x}-\mathbf{z}]$.

126. Discal cell: $(0)=$ small $[\mathbf{s}-\mathbf{w}],(1)=$ large $[\mathbf{a}-\mathbf{r}, \mathbf{x}-\mathbf{z}]$.

127. Radial cell: $(0)=$ absent $[\mathbf{h}-\mathbf{r}, \mathbf{I}],(1)=$ present $[\mathbf{a}-\mathbf{g}, \mathbf{s - z}]$.

128. Medial cell: $(0)=$ absent $[\mathbf{h}, \mathbf{I}],(1)=$ present $[\mathbf{a}-\mathbf{g}, \mathbf{i}-\mathbf{z}]$.

129. Basal or basal medial cell: $(0)=$ absent $[\mathbf{h}, \mathbf{I}],(1)=$ present $[\mathbf{a - g}, \mathbf{i}-\mathbf{z}]$.

130. Medial cell: $(0)=$ short $[\mathbf{k}-\mathbf{w}],(1)=$ elongate $[\mathbf{a}-\mathbf{g}, \mathbf{i}, \mathbf{j}, \mathbf{x}-\mathbf{z}]$.

131. Cubital cell: $(0)=$ short $[\mathbf{k}-\mathbf{r}],(1)=$ long $[\mathbf{a}-\mathbf{g}, \mathbf{i}, \mathbf{j}, \mathbf{j}-\mathbf{s}]$.

132. $\mathbf{R}_{4}$ vein: $(0)=$ without recurrent appendix [b-f, h-x, $\left.\mathbf{z}, \mathbf{I}\right],(1)=$ with recurrent appendix $[\mathbf{a}, \mathbf{g}, \mathbf{y}]$.

133. Relative lengths of basal and discal cells: $(0)=$ basal cells greater than half length of cells $\mathrm{d}$ or $\mathrm{dm}$ [a,

b, f-h, j-v, z, I],

$(1)=$ basal cells shortened, less than half length of $d$ or dm cells $[\mathbf{c}-\mathbf{e}, \mathbf{i}, \mathbf{x}-\mathbf{z}]$.

134. Spurious vein: $(0)=$ absent $[\mathbf{a}-\mathbf{h}, \mathbf{k - z}, \mathbf{I}],(1)=\operatorname{present}[\mathbf{i}, \mathbf{j}]$.

135. Spurious vein: $(0)=$ not vestigial $[\mathbf{i}],(1)=$ vestigial $[\mathbf{j}]$.

136. $\mathrm{CuA}_{2}$ fused with A1: (0) = absent [f-h, z, I], (1) = present [a-e, i-y].

137. Posterior cubital cell: $(0)=$ truncate or opened $[\mathbf{f}, \mathbf{g}, \mathbf{z}],(1)=$ tapering or closed [a-e, h-y].

138. $\mathrm{A}_{2}:(0)=$ absent $[\mathbf{f}, \mathbf{l}, \mathbf{I}],(1)=$ present $[\mathbf{a}-\mathbf{e}, \mathbf{g}-\mathbf{k}, \mathbf{m}-\mathbf{z}]$.

139. Veins of wing:(0) = posterior veins well developed, as distinct as the veins of radial, subcostal and costal sectors [a-g, i-z, $\mathbf{I}]$,

$(1)=$ posterior veins indistinct $[\mathbf{h}]$.

140. r-m: (0)=before middle of discal cell [a, c-e, $\mathbf{g}, \mathbf{i}, \mathbf{p}, \mathbf{s}-\mathbf{z}],(1)=$ after middle of discal cell $[\mathbf{b}, \mathbf{f}, \mathbf{j}-\mathbf{o}, \mathbf{q}, \mathbf{r}]$.

141. $\mathrm{R}_{4}, \mathrm{R}_{5}:(0)=$ not looped [a-g, i, k-z, I], (1) = looped [h, j]

142. Stigmal cross vein: $(0)=$ absent $[\mathbf{a}-\mathbf{i}, \mathbf{k}-\mathbf{z}, \mathbf{I}],(1)=$ present $[\mathbf{j}]$.

143. Pterostigma: $(0)=$ absent $[\mathbf{a}-\mathbf{h}, \mathbf{j}-\mathbf{z}, \mathbf{I}],(1)=$ present $[\mathbf{i}]$.

144. The alula or axillary lobe: $(0)=$ absent $[\mathbf{z}, \mathbf{I}],(1)=$ present $[\mathbf{a}-\mathbf{y}]$.

145. Scutellum trilobed: $(0)=$ absent [a-z], $(1)=$ present $[\mathbf{I}]$.

146. Scutellum: $(0)=$ with spine like extension $[\mathbf{a}-\mathbf{r}, \mathbf{u}-\mathbf{z}, \mathbf{I}](1)=$ without spine like extension $[\mathbf{s}, \mathbf{t}]$.

147. Legs: $(0)=$ short and stout $[\mathbf{a}-\mathbf{z}],(1)=$ Long and slender $[\mathbf{I}]$.

148. Forecoxa with some dark scales, usually mostly dark: $(0)=$ absent $[\mathbf{a}-\mathbf{z}],(1)=$ present $[\mathbf{I}]$.

149. Hind femora: $(0)=$ not laterally compressed $[\mathbf{a}-\mathbf{l}, \mathbf{o}, \mathbf{p}, \mathbf{s - z}, \mathbf{I}],(1)=$ laterally compressed $[\mathbf{m}, \mathbf{n}, \mathbf{q}, \mathbf{r}]$. 


\section{Phylogeny of the Basal Lineages of Suborder Brachycera (Diptera) in Egypt}

150. Hind femur with adpressed pile of scaly hairs: $(0)=$ absent $[\mathbf{a - d}, \mathbf{f}-\mathbf{z}, \mathbf{I}],(1)=$ present $[\mathbf{e}]$.

151. Mid tibial spurs: $(0)=$ absent $[\mathbf{a}-\mathbf{j}, \mathbf{s}-\mathbf{w}, \mathbf{z}, \mathbf{I}],(1)=$ present $[\mathbf{k}-\mathbf{r}, \mathbf{x}, \mathbf{y}]$.

152. Arolium: (0) = absent $[\mathbf{a}, \mathbf{b}, \mathbf{f}, \mathbf{g}, \mathbf{k - n}, \mathbf{q}, \mathbf{r}],(1)=$ present $[\mathbf{c}-\mathbf{e}, \mathbf{h}-\mathbf{j}, \mathbf{~ o , ~} \mathbf{p}, \mathbf{s - z}]$.

153. Mediolobus (pad like empodium): $(0)=$ absent [I],$(1)=$ present [a-z].

154. Empodium: (0) = bristle like [a, b, k-n, q, r], (1) = pulvilliform [c-j, o, p, s-z]

- Adult- Abdomen, non-genitalic: 155 . Abdominal length: $(0)=$ stoughtly elongate $[\mathbf{a}, \mathbf{b}, \mathbf{z}],(1)=$ non stoughtly elongate $[\mathbf{I}],(2)=$ stoughtly short [c-y].

156. T1-2: $(0)=$ separate [a-g, s-z, I],$(1)=$ fused into syntergum [h-r ].

157. Abdomen: $(0)=$ without pattern $[\mathbf{a}, \mathbf{b}, \mathbf{f}, \mathbf{g}, \mathbf{m}-\mathbf{r}],(1)=$ with pattern $[\mathbf{c}-\mathbf{e}, \mathbf{h}-\mathbf{l}, \mathbf{s - z}, \mathbf{I}]$.

158. Abdominal pattern: $(0)=$ not similar in both sexes $[\mathbf{t}, \mathbf{u}],(1)=$ similar in both sexes [c-e, h-l, $\mathbf{u}-\mathbf{z}]$.

159. Number of observed abdominal segment: $(0)=5$ segments [h-r], (1) $=6$ - 8 segments [a-g, $\mathbf{s - z}, \mathbf{I}]$.

160. Abdomen with transverse stripe in male: $(0)=$ absent $[\mathbf{v}-\mathbf{z}],(1)=$ present $[\mathbf{c}-\mathbf{e}, \mathbf{h}-\mathbf{l}, \mathbf{s}-\mathbf{u}]$.

161. Abdomen with transverse stripe in female: $(0)=$ absent $[\mathbf{v - z}],(1)=$ present $[\mathbf{c}-\mathbf{e}, \mathbf{h}-\mathbf{l}, \mathbf{s}-\mathbf{u}]$.

162. Abdominal stripes: $(0)=$ without any stripes $[\mathbf{a}-\mathbf{j}, \mathbf{l}-\mathbf{w}, \mathbf{I}],(1)=$ with incomplete median longitudinal stripe $[\mathbf{z}]$,

$(2)=$ with median longitudinal stripe $[\mathbf{k}],(3)=$ with four longitudinal stripes $[\mathbf{x}, \mathbf{y}]$.

163. Terga 1 with dark maculae: $(0)=$ absent $[\mathbf{a}-\mathbf{i}, \mathbf{k}-\mathbf{p}, \mathbf{r}-\mathbf{z}, \mathbf{I}],(1)=\operatorname{present}[\mathbf{j}, \mathbf{q}]$.

164. Anterior part of terga 2 in male: $(0)=$ without any bands [d-e, h, i, s-w], $(1)=$ with complete transverse band $[\mathbf{k}, \mathbf{l}, \mathbf{I}]$,

(2) $=$ with incomplete transverse band [j].

165. Terga 2 with complete transverse band in posterior part in male: $(0)=$ absent $[\mathbf{c}-\mathbf{e}, \mathbf{i}-\mathbf{l}, \mathbf{s}-\mathbf{w}, \mathbf{I}],(1)=$ present [h].

166. Anterior part of terga 2 in female: $(0)=$ without any bands $[\mathbf{c}-\mathbf{e}, \mathbf{h}, \mathbf{i}, \mathbf{l}, \mathbf{s}-\mathbf{w}],(1)=$ with complete transverse band [j, I],

(2) = with incomplete transverse band [k].

167. Posterior part of terga 2 in female: $(0)=$ without any bands $[\mathbf{c}, \mathbf{d}, \mathbf{i}, \mathbf{k}, \mathbf{l}, \mathbf{u}-\mathbf{w}, \mathbf{I}],(1)=$ with complete transverse band $[\mathbf{h}, \mathbf{j}]$,

$(2)=$ with incomplete transverse band $[\mathbf{e}, \mathbf{s}, \mathbf{t}]$.

168. Anterior part of terga 3 in male: $(0)=$ without any bands $[\mathbf{c - e}, \mathbf{h}, \mathbf{i}, \mathbf{s - w}],(1)=$ with complete transverse band $[\mathbf{k}, \mathbf{l}, \mathbf{I}]$,

(2) = with incomplete transverse band $[\mathbf{j}]$.

169. Posterior part of terga 3 in male: $(0)=$ without any bands $[\mathbf{c}, \mathbf{d}, \mathbf{i}-\mathbf{l}, \mathbf{s}-\mathbf{w}, \mathbf{I}],(1)=$ with complete transverse band [h],

(2) $=$ with incomplete transverse band [e].

170. Anterior part of terga 3 in female: $(0)=$ without any bands $[\mathbf{c}-\mathbf{e}, \mathbf{h}-\mathbf{j}, \mathbf{l}, \mathbf{u}-\mathbf{w}],(1)=$ with complete transverse band [I]

(2) = with incomplete transverse band $[\mathbf{k}, \mathbf{s}, \mathbf{t}]$.

171. Posterior part of terga 3 in female: $(0)=$ without any bands [c-e, i, $\mathbf{k}, \mathbf{l}, \mathbf{s}, \mathbf{t}, \mathbf{v}, \mathbf{w}, \mathbf{I}],(1)=$ with complete transverse band $[\mathbf{h}, \mathbf{j}]$,

(2) = with incomplete transverse band [u].

172. Anterior part of terga 4 in male: $(0)=$ without any bands $[\mathbf{c}-\mathbf{e}, \mathbf{h}, \mathbf{l}, \mathbf{t}-\mathbf{w}],(1)=$ with complete transverse band $[\mathbf{i}, \mathbf{k}, \mathbf{I}]$,

(2) = with incomplete transverse band $[\mathbf{j}, \mathbf{s}]$.

173. Posterior part of terga 4 in male: $(0)=$ without any bands [c, d, i-l, s, u-w, I], (1) = with complete transverse band [h],

(2) = with incomplete transverse band $[\mathbf{e}, \mathbf{t}]$.

174. Anterior part of terga 4 in female: $(0)=$ without any bands $[\mathbf{c - e}, \mathbf{h}, \mathbf{i}, \mathbf{k}, \mathbf{l}, \mathbf{s}-\mathbf{w}],(1)=$ with complete transverse band [I],

(2) = with incomplete transverse band [j].

175. Posterior part of terga 4 in female: $(0)=$ without any bands [c-e, i, $\mathbf{k}, \mathbf{l}, \mathbf{t}-\mathbf{w}, \mathbf{I}],(1)=$ with complete transverse band $[\mathbf{h}, \mathbf{j}]$, 


\section{Sara A. Al-Ashaal et al.}

(2) $=$ with incomplete transverse band [s].

176. Terga 5 with complete transverse band in anterior part in male: $(0)=\operatorname{absent}[\mathbf{c}-\mathbf{e}, \mathbf{h}-\mathbf{l}, \mathbf{s}, \mathbf{t}, \mathbf{v}, \mathbf{w}],(1)=$ present $[\mathbf{u}, \mathbf{I}]$.

177. Terga 5 with complete transverse band in posterior part in male: $(0)=$ absent $[\mathbf{c}-\mathbf{e}, \mathbf{i}-\mathbf{l}, \mathbf{s}, \mathbf{t}, \mathbf{v}, \mathbf{w}, \mathbf{I}]$, (1) = present $[\mathbf{h}, \mathbf{u}]$.

178. Anterior part of terga 5 in female: $(0)=$ without any bands $[\mathbf{c}-\mathbf{e}, \mathbf{h}-\mathbf{l}, \mathbf{s}-\mathbf{v}],(1)=$ with complete transverse band [I],

(2) = with incomplete transverse band [w].

179. Posterior part of terga 5 in female: $(0)=$ without any bands $[\mathbf{c}-\mathbf{e}, \mathbf{i}-\mathbf{l}, \mathbf{s}-\mathbf{u}, \mathbf{I}],(1)=$ with complete transverse band [h, w],

(2) = with incomplete transverse band [v].

180. Terga 6 with complete transverse band in anterior part in male: $(0)=$ absent $[\mathbf{c}-\mathbf{e}, \mathbf{h}-\mathbf{l}, \mathbf{s}, \mathbf{t}, \mathbf{v}, \mathbf{w}],(1)$ present $[\mathbf{u}, \mathbf{I}]$.

181. Terga 6 with complete transverse band in posterior part in male: $(0)=$ absent $[\mathbf{c}-\mathbf{e}, \mathbf{i}-\mathbf{l}, \mathbf{s}, \mathbf{t}, \mathbf{v}, \mathbf{w}, \mathbf{I}]$, $(1)=$ present $[\mathbf{h}, \mathbf{u}]$.

182. Anterior part of terga 6 in female: $(0)=$ without any bands $[\mathbf{c}-\mathbf{e}, \mathbf{h}-\mathbf{l}, \mathbf{s}-\mathbf{v}],(1)=$ with complete transverse band [I],

$(2)=$ with incomplete transverse band [w].

183. Posterior part of terga 6 in female: $(0)=$ without any bands [c-e, i-l, s-u, I], $(1)=$ with complete transverse band [h, w],

(2) = with incomplete transverse band [v].

184. Terga 7 with complete transverse band in anterior part: $(0)=$ absent $[\mathbf{c}-\mathbf{e}, \mathbf{h}-\mathbf{l}, \mathbf{s}-\mathbf{w}],(1)=$ present $[\mathbf{I}]$.

185. Terga 8 with complete transverse band in anterior part: $(0)=$ absent $[\mathbf{c}-\mathbf{e}, \mathbf{h}-\mathbf{l}, \mathbf{s}-\mathbf{w}],(1)=$ present $[\mathbf{I}]$.

186. Abdomen with spots: $(0)=$ absent $[\mathbf{a}-\mathbf{l}, \mathbf{n}, \mathbf{q}-\mathbf{z}, \mathbf{I}],(1)=$ present in male and female $[\mathbf{m}],(2)=$ present in male only [p],

(3) $=$ present in female only [o].

187. Female abdomen: $(0)=$ without any patterns $[\mathbf{a}-\mathbf{m}, \mathbf{o}, \mathbf{q - z}, \mathbf{I}],(1)=$ with horseshoe-shape mark on tergite 3 and 4 [p],

(2) = Check-board abdomen [n].

188. Female ovipositor: $(0)=$ short $[\mathbf{a}-\mathbf{j}, \mathbf{m}-\mathbf{z}, \mathbf{I}],(1)=$ as long as the two last abdominal segment $[\mathbf{l}],(2)=$ longer than abdomen $[\mathbf{k}]$.

189. Hypopygial prominence in male: $(0)=$ absent $[\mathbf{a - o}, \mathbf{q - z}, \mathbf{I}],(1)=$ present $[\mathbf{p}]$.

- Adult-male genitalia: 190. Male tergite 6: $(0)=$ at least half length tergite 5 and grading into the terminalia, usually exposed $[\mathbf{a}-\mathbf{g}, \mathbf{i}, \mathbf{m}, \mathbf{n}, \mathbf{x}-\mathbf{z}, \mathbf{I}],(1)=$ at most half length tergite 5 and part of a welldefined unit "terminalia", rarely exposed [h, $\mathbf{j}-\mathbf{l}, \mathbf{o}-\mathbf{w}]$.

191. Syntergosternite comprised of at least fusion of sternite and tergite of segment 8: $(0)=$ absent [a-g, $\mathbf{s -}$ $\mathbf{z}, \mathbf{I}],(1)=$ present $[\mathbf{h}-\mathbf{r}]$.

192. Syntergosternite: $(0)=$ comprised of fusion of sternite and tergite of segment 8 [a-j, s-z, I], (1) = comprised of fusion of sternites and tergites of segment 7 and 8 [k-r].

193. Hypopygium circumversion, rotated permanently through $360^{\circ}:(0)=$ absent $[\mathbf{a}-\mathbf{g}, \mathbf{s - z}, \mathbf{I}],(1)=$ present [h-r].

194. Position of hypopygium: $(0)=$ asymmetrical, on right side of abdomen [h-r], (1) = symmetrical, in medial line of abdomen [a-g, s-z, I].

195. Epandrium articulation: $(0)=$ fused to or lying flat on hypandrium [I],$(1)=$ articulated on gonocoxites or hypandrium [a-z].

196. Epandrium: (0) = shallowly notched or posterior margin straight $[\mathbf{c}-\mathbf{g}, \mathbf{s - z}, \mathbf{I}],(1)=$ posterior margin deeply emarginate, forming U-shape with basal connection $[\mathbf{a}, \mathbf{b}, \mathbf{h}-\mathbf{r}]$.

197. Epandrium and hypandrium: $(0)=$ fused ring [I],$(1)=$ separate [a-z].

198. Hypandrium and gonocoxites:(0) = separate [I], (1) = completely fused, no seams [a-z].

199. Hypandarium: $(0)=$ subrectangular $[\mathbf{a}-\mathbf{g}, \mathbf{I}],(1)=$ subtriangular $[\mathbf{s - z}],(2)=$ fused with gonocoxite to form ventral plate [h-r]. 


\section{Phylogeny of the Basal Lineages of Suborder Brachycera (Diptera) in Egypt}

200. Hypandarium U- shaped with the post brackets going beyond the base of the phallus: $(0)=$ absent [aj, s-z, I], (1) = present [k-r].

201. Hypandarium wide and posteriorly rounded: $(0)=$ absent $[\mathbf{a}-\mathbf{g}, \mathbf{k - z}, \mathbf{i}],(1)=$ present $[\mathbf{h}-\mathbf{j}]$.

202. Gonostyli: (0) = absent [a, b, f-h], (1)=apical [I], (2) = subapical [c, e, i-z], (3)=Subapical forked [d]. 203. Aedeagus: $(0)=$ surrounded by parameres $[\mathbf{a}-\mathbf{w}, \mathbf{z}, \mathbf{I}],(1)=$ fused to parameres at apex, forming phallus $[\mathbf{x}, \mathbf{y}]$.

204. Parameres: $(0)=$ paired and separate $[\mathbf{x}-\mathbf{z}, \mathbf{I}],(1)=$ fused $[\mathbf{a}-\mathbf{w}]$.

205. Phallus: $(0)=$ undivided $[\mathbf{a}, \mathbf{b}, \mathbf{r}-\mathbf{w}],(1)=$ subdivided into a dorsal guide and a ventral needle-like component [c-q].

206. Phallapodeme: $(0)=$ absent $[\mathbf{I}],(1)=$ present $[\mathbf{a}-\mathbf{z}]$.

207. Ejaculatory apodeme: $(0)=$ absent $[\mathbf{I}],(1)=$ present $[\mathbf{a}-\mathbf{z}]$.

- Adult- female genitalia: 208. Apical female abdominal segments: (0) = all segments exposed, gradually telescopic [k, l], (1) = Segment 8-10 retracted [z, I], (2) = Segments 7-10 retracted [a-g, s-y], (3) $=$ Segments 6-10 retracted $[\mathbf{h}, \mathbf{i}, \mathbf{m}, \mathbf{n}],(4)=$ Segments 5-10 retracted $[\mathbf{j}, \mathbf{o}-\mathbf{r}]$.

209. ST10: $(0)=$ absent $[\mathbf{c}-\mathbf{r}, \mathbf{I}],(1)=$ present $[\mathbf{a}, \mathbf{b}, \mathbf{s}-\mathbf{z}]$.

210. Female Cerci: $(0)=$ one-segmented $[\mathbf{a}-\mathbf{r}, \mathbf{u}-\mathbf{y}, \mathbf{I}],(1)=$ two-segmented, free from each other $[\mathbf{s}, \mathbf{t}]$.

211. Spermathecae: $(0)=$ absent $[\mathbf{h}-\mathbf{j}, \mathbf{m}-\mathbf{w}],(1)=$ present $[\mathbf{a}, \mathbf{b}, \mathbf{f}, \mathbf{g}, \mathbf{k}, \mathbf{l}, \mathbf{x}]$.

212. Spermathecal ducts: $(0)=$ of moderate length, at most less than the length of the abdomen $[\mathbf{a}, \mathbf{b}, \mathbf{f}, \mathbf{g}]$, $(1)=$ very long, at least much longer than the abdomen $[\mathbf{x}]$.

213. Segment 8 transformed into piercing stick: $(0)=\operatorname{absent}[\mathbf{a}-\mathbf{j}, \mathbf{m}-\mathbf{y}, \mathbf{I}],(1)=\operatorname{present}[\mathbf{k}, \mathbf{l}]$.

214. Uterus or ovisac: $(0)=$ absent $[\mathbf{a}-\mathbf{l}, \mathbf{o}-\mathbf{y}, \mathbf{I}],(1)=$ present $[\mathbf{m}, \mathbf{n}]$.

215. Bursa inseminalis: $(0)=$ absent $[\mathbf{c}-\mathbf{y}],(1)=$ present $[\mathbf{a}, \mathbf{b}, \mathbf{I}]$.

216. Pair of tubular gland: (0) = absent [a-e, h-y, I], (1) = present [f, g].

Note: the species that not mentioned in the character states with non compared characters. 
Sara A. Al-Ashaal et al.

Appendix 3

Cladogram (based on morphological datasets).

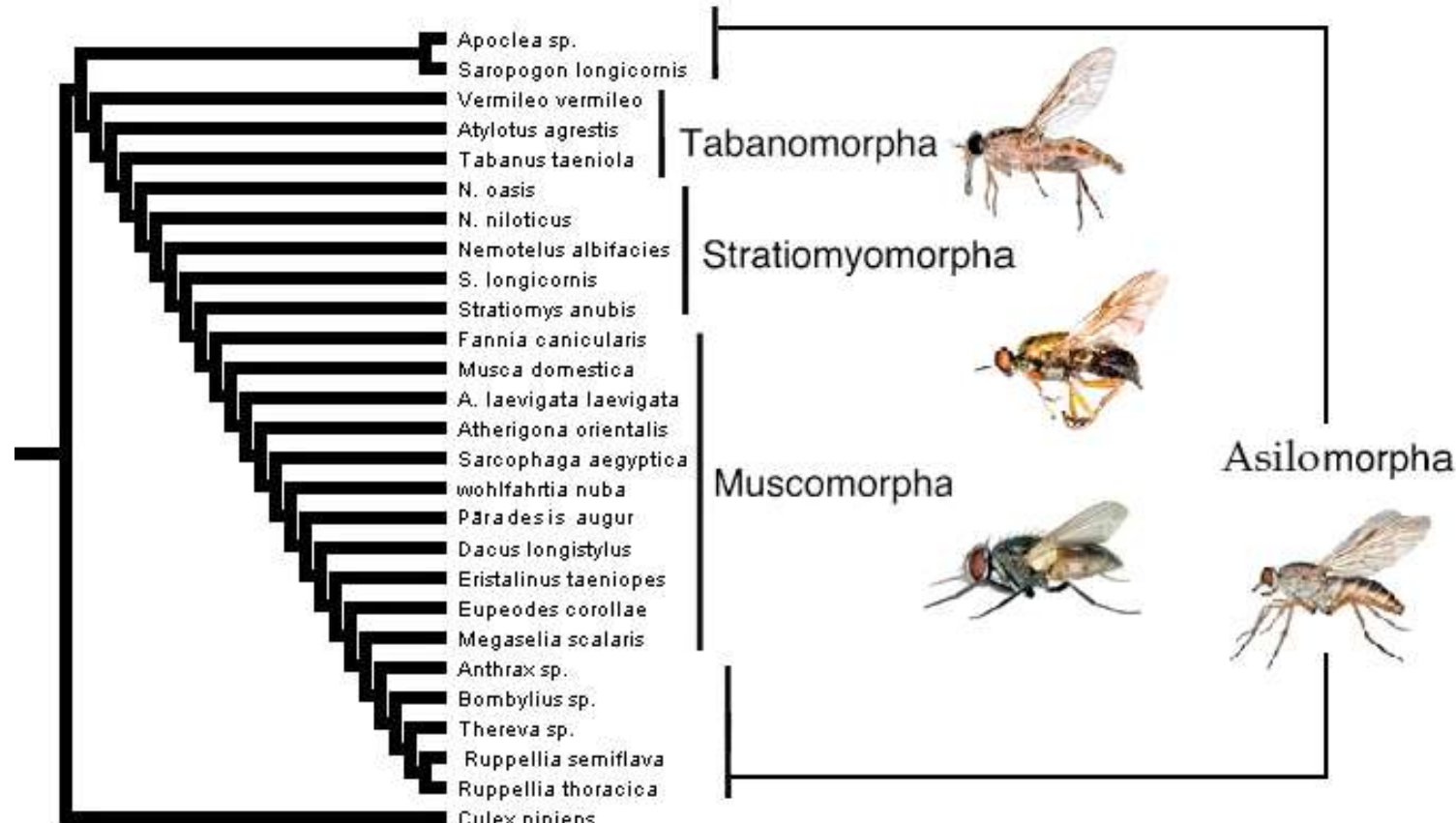

Appendix 4

Cladogram (based on sequence data).

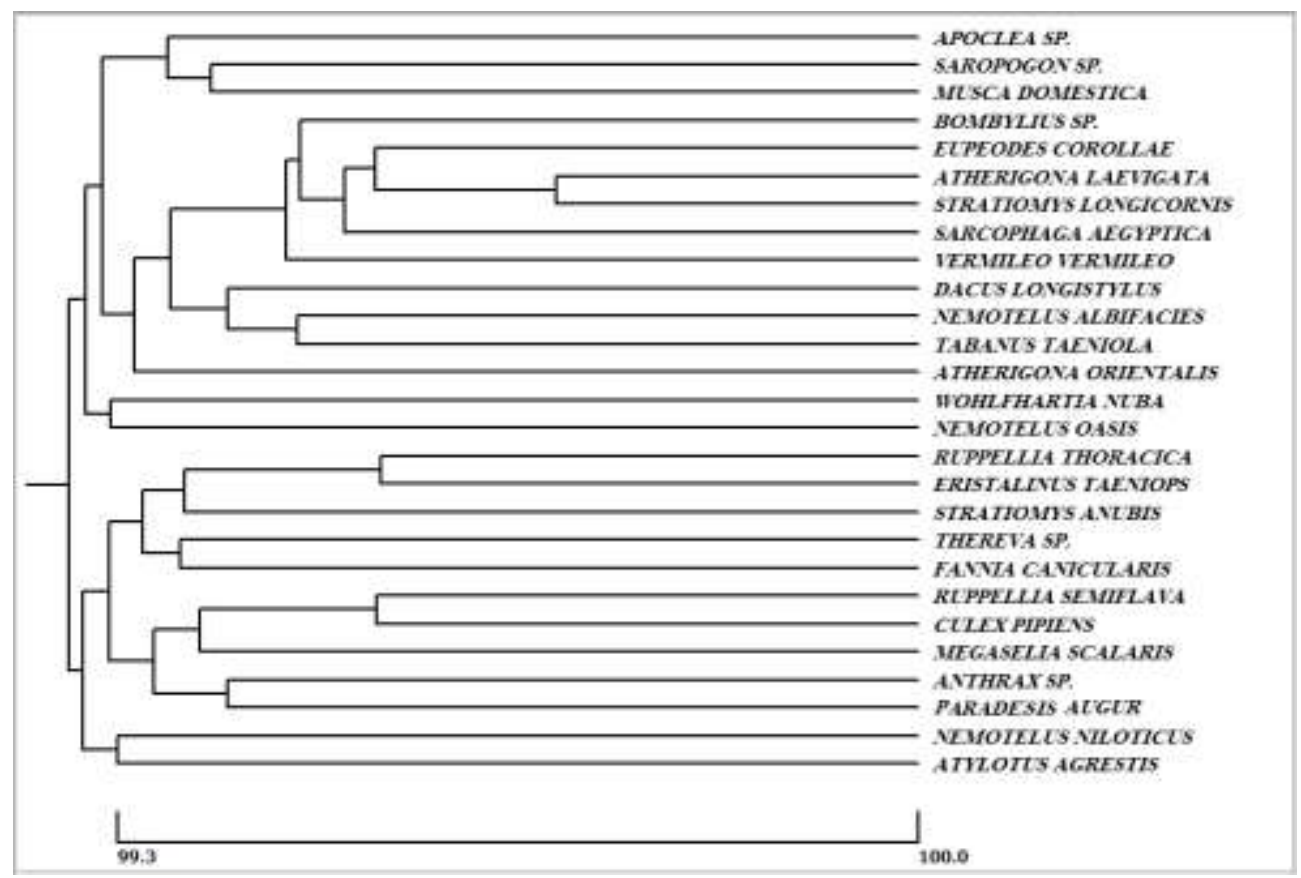


Phylogeny of the Basal Lineages of Suborder Brachycera (Diptera) in Egypt

\section{Appendix 5}

Cladogram (based on combined data - morphological/gene sequence).

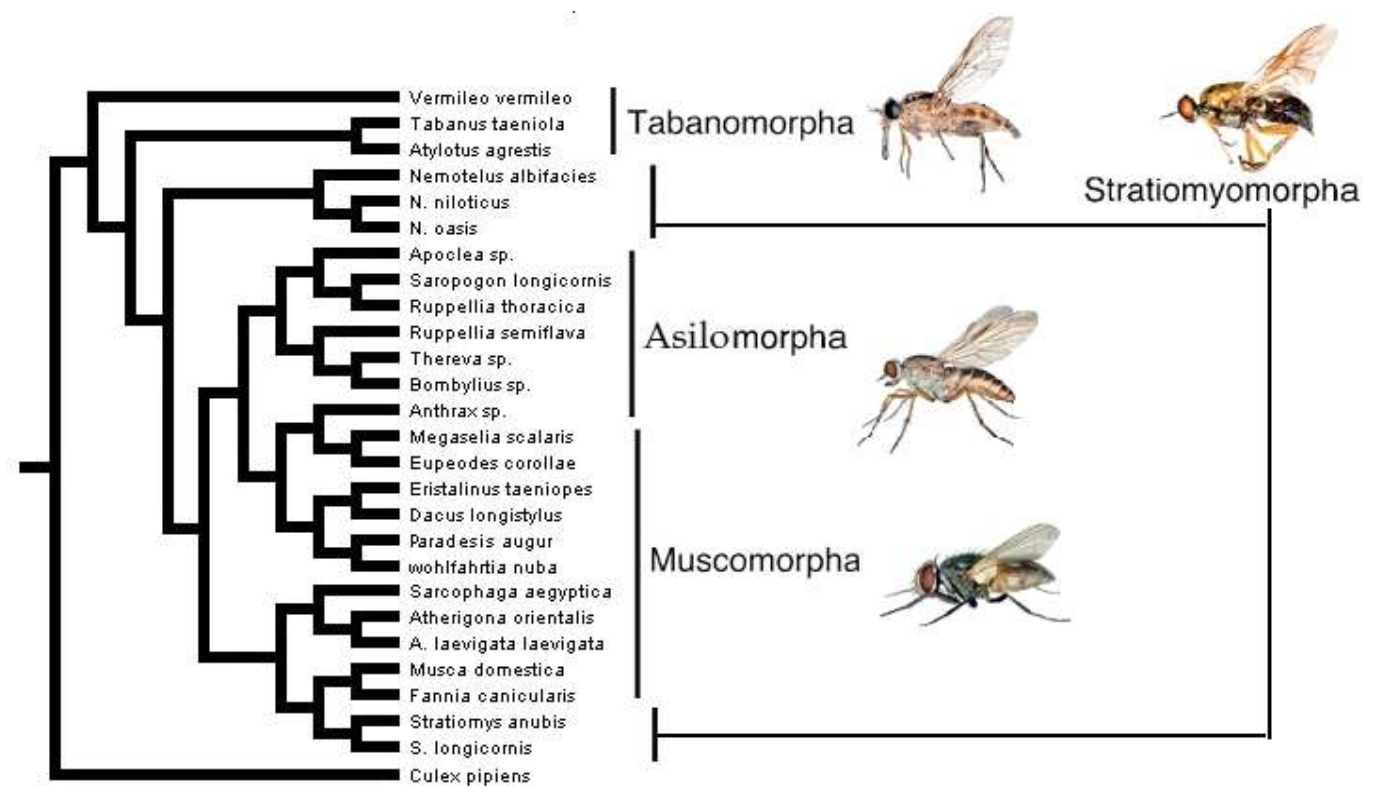


Sara A. Al-Ashaal et al.

Arabic Abstract 